\title{
Linear adhesive connections at the edge of laminated glass panes: an experimental study under tensile, compressive and shear loading
}

\author{
Vlad Alexandru Silvestru • Oliver Englhardt • \\ Jens Schneider
}

Received: 8 February 2018 / Accepted: 12 June 2018 / Published online: 25 June 2018

(C) The Author(s) 2018

\begin{abstract}
Adhesive connections experience in recent years an increasing popularity in the field of structural glass. Generally, linear adhesive joints are positioned on the surface of glass panes as in the case of structural sealant glazing systems. However, due to the existing trend for larger glass elements and implicitly glass panes with higher thickness, connections with adhesive joints at the edge of laminated glass panes become more interesting. In this article, experimental results for such linear adhesive joints with glass and stainless steel substrates, tested under tensile, compressive and shear loading, are presented and discussed. Three different cross section geometries of the joints are investigated: rectangular, L-shaped and U-shaped. For each of these cross sections, two silicone adhesives approved for structural sealant glazing systems and one structural acrylic adhesive are included in the experimental programme. All tests are performed at ambient conditions. Beside the mechanical behaviour in the form of load
\end{abstract}

V. A. Silvestru $(\varangle) \cdot$ O. Englhardt

Institute of Building Construction, Graz University of

Technology, Lessingstraße 25, 8010 Graz, Austria

e-mail: silvestru@tugraz.at

J. Schneider

Institute of Structural Mechanics and Design, Technische

Universität Darmstadt, Franziska-Braun-Straße 3, 64287

Darmstadt, Germany

e-mail: schneider@ismd.tu-darmstadt.de

Present address:

O. Englhardt

\&structures, Friedrichstraße 33, 80801 Munich, Germany

e-mail: office@andstructures.com versus displacement results, also the failure modes and patterns are analysed. Regarding the interaction of the adhesives with the interlayer material under compressive loading, it is observed that at certain loads bubbles start to form in the interlayer and subsequently a delamination is initiated for all three adhesives. Moreover, the specimens with acrylic adhesive exhibit delamination as well under tensile and under shear loading. The results from this experimental study provide novel findings for linear adhesive connections at the edge of laminated glass panes and represent a basis for further investigations and developments on such joints.

Keywords Adhesive connections - Structural silicones - Structural acrylics - Laminated glass · Delamination · Destructive testing

\section{Introduction}

Glass as a building material has expanded its area of application in the past few decades from infilling window and façade glazing to structurally efficient beams, fins and shear panels. Especially when glass components are used for structural purposes, a significant part of the engineering is dedicated to the connections. Mechanical ones like bolted connections generally lead to high local stresses in the area of the boreholes, which the brittle material glass is not able to redistribute. Adhesive connections represent in recent years an attractive alternative for joining glass compo- 
nents, since they allow for a more uniform stress distribution (Haldimann et al. 2008; Overend et al. 2011). Based on their geometry, adhesive connections for glass substrates can be classified in laminar bonding, linear joints and point fixings. Variable adhesive types are suitable for the different connections. For the first category, mainly interlayer materials used for the production of laminated glass are considered, but also UVcuring acrylics for bonding between glass blocks (Göppert and Paech 2008; Oikonomopoulou et al. 2017) or for realizing glass frame corners (Voit et al. 2014; Weller et al. 2010) belong here. A related, rather novel type of adhesive connection can be realized by embedding thin (Puller and Sobek 2012) or thick (Santarsiero et al. 2016a) metal inlets in the assembly of the laminated glass panes. In the case of point fixings, different adhesives are considered depending mainly whether the connection is exposed to outdoor conditions or not. Recent investigations focus on MS-polymers (Dispersyn et al. 2017) and epoxies (Dispersyn and Belis 2016) as well as on laminated connections with transparent structural silicone adhesive (TSSA) (Santarsiero et al. 2016b, 2017; Drass et al. 2017a, b; IoannidouKati et al. 2018a) and the ionomer SentryGlas ${ }^{\circledR}$ (SG) (Santarsiero et al. 2016b, 2017).

In terms of linear adhesive joints, structural sealant glazing systems (SSGS) are one of the leading applications. Elastomeric silicone adhesives with relatively low strength and high flexibility are used to bond glass panes circumferentially to frame profiles made of aluminium, stainless steel or timber. This type of system is also the only structural application of adhesives for glass substrates in the building sector which is generally approved by authorities based on guidelines (ASTM C 1401-02 2002; ETAG 002 2001). The aim to increase the structural efficiency by achieving a composite action between glass and metal components with linear adhesive joints resulted in several research projects focusing on the identification of suitable adhesives with higher shear strength than silicones. Adhesives for metal substrates are assessed for instance by Belis et al. (2011) and Overend et al. (2011), for timber substrates, among others, by Nicklisch et al. (2014) and for glass fibre reinforced plastics by Peters (2006). These investigations focus on adhesive joints on the surface of glass panes. Such joints can be found in a large number of aimed applications like for instance glass panes used as shear panels (Huveners 2009; Mocibob 2008; Piculin et al. 2016; Wellershoff
2006), composite glass beams (Abeln et al. 2013; Cruz et al. 2008) or out-of-plane loaded steel-glass composite panels (Nhamoinesu et al. 2014). With the technological advance in the glass industry and the trend for larger glass panes and longer glass beams also the total thickness of the glass elements is increasing, generally by laminating a higher number of glass sheets. This leads to possible solutions with linear adhesive joints at the edge of laminated glass panes for similar applications. Examples of research carried out on joints at the edge of monolithic glass panes are the investigations by Huveners (2009) on an epoxy to activate a glass pane as a shear panel and by Ioannidou-Kati et al. (2018b) on the use of TSSA for laminated connections under shear loading. In terms of joints at the edge of laminated glass panes several research projects on edge-reinforced glass beams have been completed in the past and are well documented in a review paper by Martens et al. (2016). Furthermore, Cupac et al. (2017) used recently an acrylic adhesive joint at the edge of laminated glass to obtain a post-tensioned glass beam.

While in the case of bonding on the glass surface, generally, the adhesive joints are subjected mainly to shear loading, for bonding on the edge of laminated glass panes also tensile and compressive loading need to be often considered. Furthermore, a significant issue is the compatibility between the adhesive and the interlayer material as well as the mechanical interaction between these two materials. The amount of research results on such connections is rather limited, especially with respect to tensile and compressive loading. Investigations on the performance of adhesive joints at the edge of laminated glass panes under tensile loading with two different silicone adhesives and different cross sections of the joints are documented in Hagl (2007). However, the aimed application as a connection between the façade glazing and glass fins supposes both tensile and compressive loading of the joint due to wind suction and wind pressure for example.

The investigations discussed in this article show the mechanical behaviour and the failure modes of adhesive connections at the edge of laminated glass panes under tensile, compressive and shear loading. Three different joint cross sections and three different adhesives are included in the experimental programme. For such adhesive joints under compressive loading, no previous research is available. Although, in most situations with adhesive connections subjected to compres- 
sive loading, form fit ensures load transfer capacities even after the adhesive fails, the criticality of this loading type is given by the damages resulting in the adhesive or in the interlayer material before the form fit is activated. Such damages, like local adhesive rupture or delamination of the interlayer are irreversible and critical both from a structural and an aesthetical point of view.

\section{Materials}

The investigations on adhesive joints at the edge of laminated glass panes, which are discussed in this article, are part of a larger research project on glass-metal elements with composite structural behaviour to be used in facades. This aspect is reflected in the choice of both the substrate materials and the adhesives. For all specimens, stainless steel components are bonded together with laminated glass panes. In the case of the stainless steel, the material no. 1.4404 with the short name $\mathrm{X} 2 \mathrm{CrNiMo} 17-12-2$ according to (EN 10088-4 2009) is used. This type of stainless steel shows the advantages of a higher resistance to corrosion as well as stability in chloride containing and sulphuric atmosphere. Furthermore, it can be welded in thicknesses higher than $6 \mathrm{~mm}$ due to its lower carbon content compared to other stainless steel types. The bonded surfaces of the stainless steel components show a grinded finishing with an abrasive paper $\mathrm{P} 300$. The laminated glass panes consist each of two heat strengthened glass panes (HSG) with a nominal thickness of $10 \mathrm{~mm}$ and a polyvinyl butyral interlayer (PVB) with a nominal thickness of $1.52 \mathrm{~mm}$. The two monolithic glass panes show facetted edges on both sides. The lamination process is completed with vacuum bags. This results in an edge aspect as illustrated in Fig. 1.

Aiming for a structural application in facades, two of the primary criteria for selecting suitable adhesives are on the one hand a sufficient strength for transferring the expected loads and on the other hand a sufficient flexibility to avoid indirect stresses in the glass due to temperature loads. None of the adhesives available on the market can fully satisfy these two contradictory requirements along with a service temperature range between -20 and $+80^{\circ} \mathrm{C}$ as well as a durable resistance against moisture, cleaning agents and UVradiation. Depending on the application, priorities need to be defined and certain compromises may be neces-

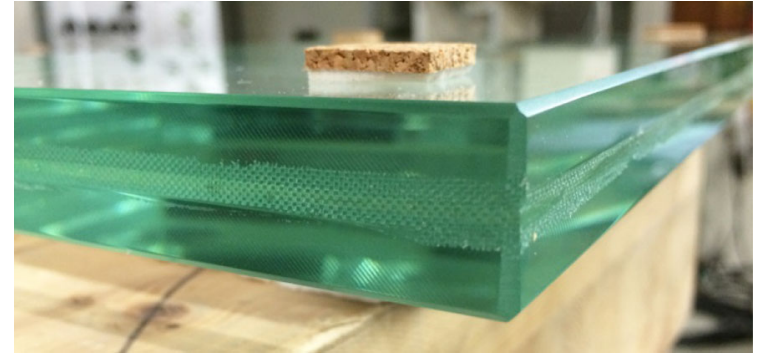

Fig. 1 Close view of the edge from one of the laminated glass panes used for the test specimens

sary. For the investigations discussed in this article two structural silicones approved for the use in structural sealant glazing systems and a structural acrylic with higher strength and stiffness are considered. Selected specifications for these three materials are provided in Table 1.

Silicone 1 is one of the most often used sealants for structural glazing systems. According to the technical data sheet, it provides a good adhesion to anodised or polyester paint coated aluminium and stainless steel as well as to coated, enamelled and reflective glass substrates. Furthermore, it shows a good compatibility to the most commonly used glazing components, like weatherproofing sealants, insulating glass sealants and interlayer materials. For a proper mixing and dispensing, the use of a two-component silicone dispensing machine with an airless mixing system is advised. If only small material quantities are required, special two-part hand mixed cartridge systems are available. The curing takes place at room temperature by releasing a small amount of alcohol. This silicone adhesive is well investigated both regarding its performance under different types of loading and under different environmental conditions (Dias et al. 2014; Hagl 2007, 2016; Staudt et al. 2014, 2018). Due to the numerous results and the wide experience with this adhesive, it is often included as a reference material in research investigations on adhesives for structural glass applications.

Silicone 2 shows similar characteristics to silicone 1 regarding mixing and curing, but it is recommended for applications where silicones with higher strength are required. Due to the higher viscosity of the material, hand mixed cartridge systems cannot be used for this silicone. Since it is a rather new product, there is less experience available regarding adhesion to different substrates as well as concerning compatibility 
Table 1 Selected specifications for the investigated structural adhesives based on Dow Corning ${ }^{\circledR} 993$ (2014), Sikasil ${ }^{\circledR}$ SG-550 (2016) and SikaFast ${ }^{\circledR}-5221$ NT (2013)

\begin{tabular}{llll}
\hline Property & Silicone 1 & Silicone 2 & Acrylic \\
\hline Product name & Dow Corning ${ }^{\circledR} 993$ & Sikasil ${ }^{\circledR}$ SG-550 & SikaFast ${ }^{\circledR}-5221$ NT \\
Type & Two-part silicone & Two-part silicone & Two-part acrylic \\
Working/snap/fixture time (min) & $\sim 10-30$ & $\sim 30$ & $\sim 10$ \\
Tack-free/fixture time (min) & $\sim 80-100$ & $\sim 150$ & $\sim 25$ \\
Service temperature range $\left({ }^{\circ} \mathrm{C}\right)$ & -50 to +150 & -40 to +150 & -40 to +80 \\
\hline
\end{tabular}

issues to other glazing components. Moreover, almost no published research results are available for this silicone. Only reports on single projects in which this adhesive has been used can be found in literature, for instance in Doebbel et al. (2014). However, the material properties of the related more often used silicone adhesive Sikasil ${ }^{\circledR}$ SG-500 are investigated in Van Lancker et al. $(2016,2018)$ with respect to linear glass-steel connections.

The selected structural acrylic exhibits according to the technical data sheet (SikaFast ${ }^{\circledR}-5221$ NT 2013) a rapid strength development after mixing and a high flexibility. While the adhesion properties to substrates made of stainless steel and aluminium under shear loading are indicated as good, failures due to loss of adhesion can occur for glass substrates. For application, the two components are mixed with a static mixer and can be applied both manually with a cartridge gun from dual cartridges or by pump and robot in production lines. The thickness of joints with this adhesive should not exceed $3.0 \mathrm{~mm}$ to avoid an excessive temperature increase due to the exothermic reaction during curing. Predecessors of this structural acrylic have been investigated in Abeln et al. (2013) for connecting steel flanges to glass panes in order to obtain composite glass beams and in Wellershoff (2006) for activating glass panes as shear panels. Furthermore, the influence of artificial ageing on connections with the similar product SikaFast ${ }^{\circledR}-5215$ NT has been analysed in Machalicka et al. (2018).

\section{Methods}

For the three selected adhesives, rectangular, L-shaped and U-shaped linear joints at the edge of laminated glass panes are investigated separately under tensile, compressive and shear loading. All experimental tests are performed displacement-controlled on an electromechanical testing machine BETA1000 equipped with a $100 \mathrm{kN}$ load cell for tensile and shear loading and with a $1000 \mathrm{kN}$ load cell for compressive loading. For the specimens with silicone adhesives tested under tensile loading and under shear loading, a displacement rate of $5 \mathrm{~mm} / \mathrm{min}$ is used based on the recommendations in (ETAG 002). For the specimens with acrylic adhesive tested under the same types of loading, a lower displacement rate of $1 \mathrm{~mm} / \mathrm{min}$ is chosen because of the thinner joint and the smaller expected displacements, especially in the elastic range. The compressive tests on joints at the edge of laminated glass panes with silicone adhesives are performed with a displacement rate of $1 \mathrm{~mm} / \mathrm{min}$. For the joints with acrylic adhesive a two times smaller displacement rate of $0.5 \mathrm{~mm} / \mathrm{min}$ is chosen, because the thickness of these joints is two times smaller than the thickness of the joints with silicone adhesives and a potential load increase until direct contact between the stainless steel parts and the glass pane edges is taken into account. In the case of the silicones, load cycles are carried out additionally, as follows: loading up to $25 \%$ compression, unloading, loading up to $50 \%$ compression, unloading, loading up to a load of $400 \mathrm{kN}$, unloading. The load is not increased further to avoid an eventual glass failure. The test specimens and the test setups are described in the following three subsections for the different types of applied loading. For each of the selected adhesives and each of the differently shaped joint cross sections, three identical specimens are tested under each of the three investigated loading types. This results in a total of 81 test specimens included in this experimental study. 


\subsection{Linear adhesive joints under tensile loading}

The specimens for the tensile tests consist of a laminated glass pane, which is adhesively bonded to a stainless steel part, as shown in Fig. 2. All glass panes are $300 \mathrm{~mm}$ long and $210 \mathrm{~mm}$ wide, without depending on the cross section geometry of the adhesive joint. The stainless steel parts, however, differ for the three investigated cross sections. In the case of the rectangular joints (see Fig. 2a), stainless steel sheets with a length of $140 \mathrm{~mm}$, a width of $150 \mathrm{~mm}$ and a thickness of $20 \mathrm{~mm}$ are used. The dimension of $140 \mathrm{~mm}$, which is $40 \mathrm{~mm}$ longer than the joint length, is mainly needed during manufacturing for fixing the joint thickness determining spacers. The dimension of $150 \mathrm{~mm}$ is chosen to allow a proper clamping in the testing machine and enough space for connecting the displacement transducers. The length of all adhesive joints is $100 \mathrm{~mm}$, while the width of the adhesive joints with rectangular cross section is equal to the thickness of the stainless steel sheets and values $20 \mathrm{~mm}$. For the specimens with silicone adhesive, the adhesive joints have a thickness of $6 \mathrm{~mm}$, based on the advised minimum thickness for SSGS in (ETAG 002). In the case of the specimens with acrylic adhesive a joint thickness of only $3 \mathrm{~mm}$ is used, based on the advices in (SikaFast ${ }^{\circledR}-5221$ NT 2013). For some of the dimensions provided in Fig. 2 for the adhesive and for the stainless steel parts, a second value is specified in brackets. The first provided value is valid for the specimens with silicone adhesives, while the one in brackets is valid for those with acrylic adhesive.

In the case of the test specimens with L-shaped and U-shaped cross sections of the adhesive joints, the stainless steel parts are designed as illustrated in Fig. 2b, c. To facilitate the desired joint geometries, firstly, $10 \mathrm{~mm}$ thick stainless steel sheets with varying width depending on the adhesive thickness are welded perpendicularly to sheets of the type used for the rectangular joints. Secondly, $15 \mathrm{~mm}$ thick stainless steel sheets with gashed threads are screwed to the welded parts. The screwed parts are connected only on one side of the glass pane for the specimens with L-shaped joints and on both sides for those with U-shaped joints. Three M6 bolts of quality 8.8 are used for each connection. The same thicknesses specified for the rectangular joints are used also for the L-shaped and the U-shaped ones, both on the edge side and on the lateral sides of the glass panes. The widths of the adhesion surfaces on the lateral sides of the glass panes average $20 \mathrm{~mm}$.

The support of the test specimens and the load application during testing are illustrated for the specimen with rectangular cross section in Fig. 3. The glass pane is hold down in a standing position with two square hollow section bars $(40 \mathrm{~mm} \times 40 \mathrm{~mm} \times 5 \mathrm{~mm})$. To restrain the specimens laterally, two steel sheets are fixed on the machine table at the bottom of the glass panes. Elastomeric layers are positioned between the glass pane and all tangent steel elements to avoid a glass failure due to stress peaks. The load is applied with a clamping device which pulls the stainless steel part away from the glass pane. In order to measure only the displacements occurring in the adhesive joints, without influences from the elastomeric layers, two transducers are fixed with weld pins on the stainless steel parts. Displacement transducers of type WA20 with a measurement accuracy of $\pm 1 \%$ are used. (a)

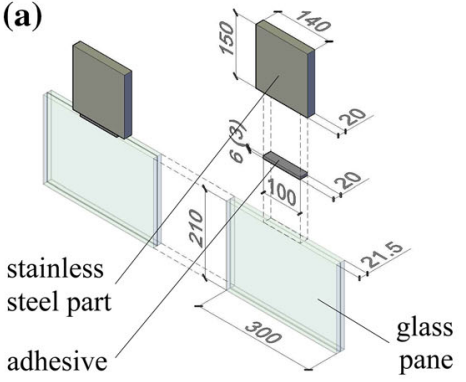

(b)

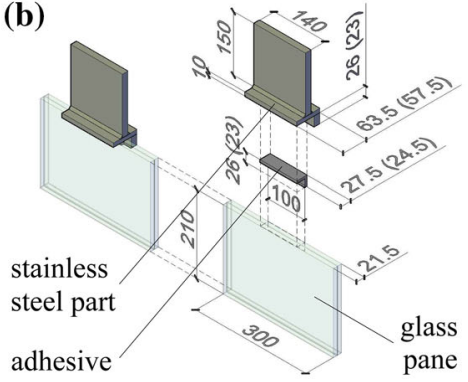

(c)

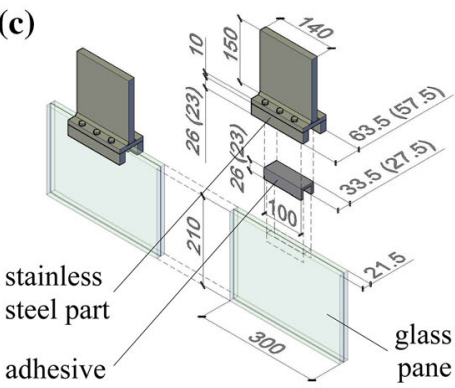

Fig. 2 Sketches of the specimens for linear adhesive connections with a rectangular, $\mathbf{b}$ L-shaped and $\mathbf{c}$ U-shaped cross section of the joint tested under tensile loading 


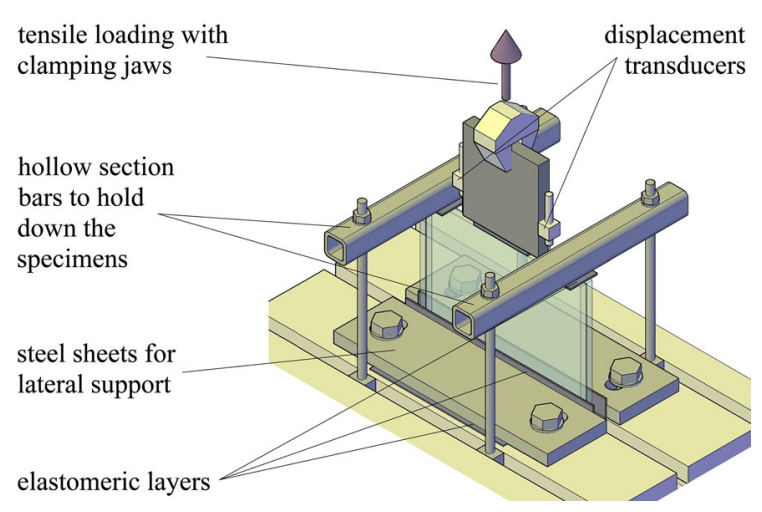

Fig. 3 Descriptive sketch of the test setup used for linear adhesive joints under tensile loading

\subsection{Linear adhesive joints under compressive loading}

The specimens for the compressive tests are illustrated in Fig. 4 and have a similar composition to those tested under tensile loading. Only the stainless steel parts are adapted for applying a compressive load, since no clamping is required. For the specimens with a rectangular cross section of the adhesive joint (see Fig. 4a), the stainless steel part has a length of $200 \mathrm{~mm}$ in order to allow enough space for applying the load and connecting the displacement transducers. The height and the thickness values are $20 \mathrm{~mm}$. The stainless steel parts for the test specimens with L-shaped (see Fig. 4b) and U-shaped (see Fig. 4c) cross sections of the adhesive joints consist of a $200 \mathrm{~mm}$ long and $10 \mathrm{~mm}$ thick stainless steel sheet to which $15 \mathrm{~mm}$ thick stainless steel elements with gashed threads are screwed. The dimensions of the linear adhesive joints are the same as in the case of the tensile tests.

During testing, the specimens are placed in a standing position on the machine table and are restrained

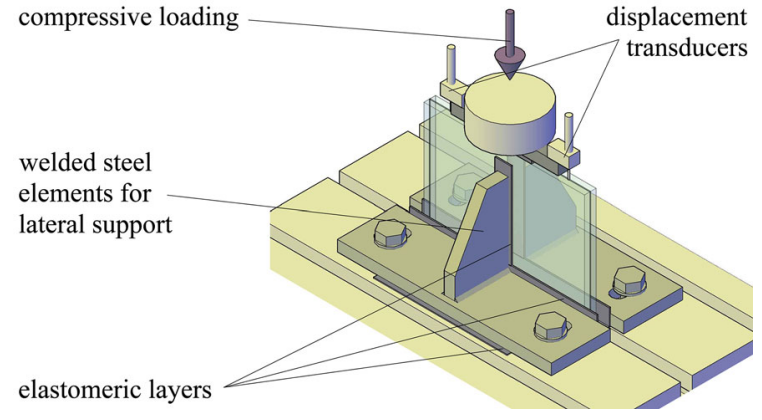

Fig. 5 Descriptive sketch of the test setup used for linear adhesive joints under compressive loading

laterally with steel elements as shown in Fig. 5. Other than in the case of the specimens tested under tensile loading, a vertical steel sheet is welded to the horizontal sheet in order to prevent an eventual buckling of the glass pane. The load is applied directly with the electromechanical testing machine by pressing the stainless steel part towards the glass pane. Two transducers are fixed with weld pins on the top of the stainless steel part to measure the relative displacements between stainless steel part and glass pane.

\subsection{Linear adhesive joints under shear loading}

For the linear adhesive joints at the edge of laminated glass panes tested under shear loading, double-lap test specimens are chosen. The test specimens for the three different joint cross sections are illustrated in Fig. 6. Each test specimen consists of two laminated glass panes of the same size and composition as those used for the tensile and compressive tests. Between these glass panes, a stainless steel part is adhesively bonded at their edges. In the case of the specimens with rect- (a)

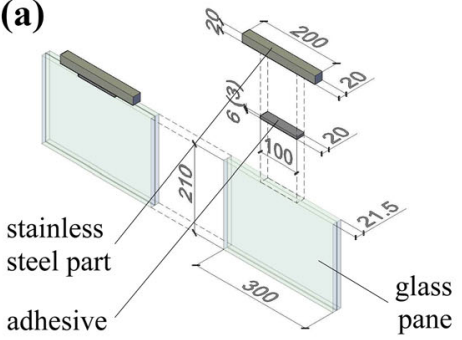

(b)

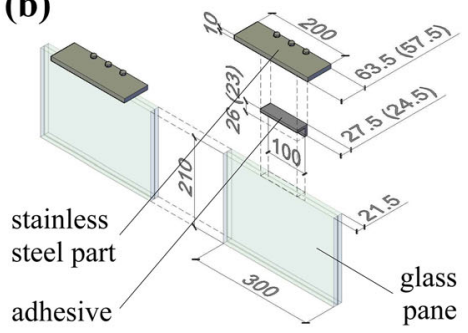

(c)

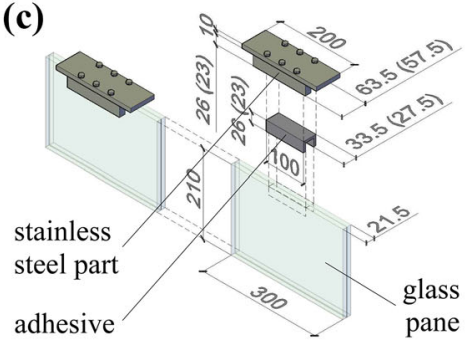

Fig. 4 Sketches of the specimens for linear adhesive connections with a rectangular, $\mathbf{b}$ L-shaped and $\mathbf{c}$ U-shaped cross section of the joint tested under compressive loading 

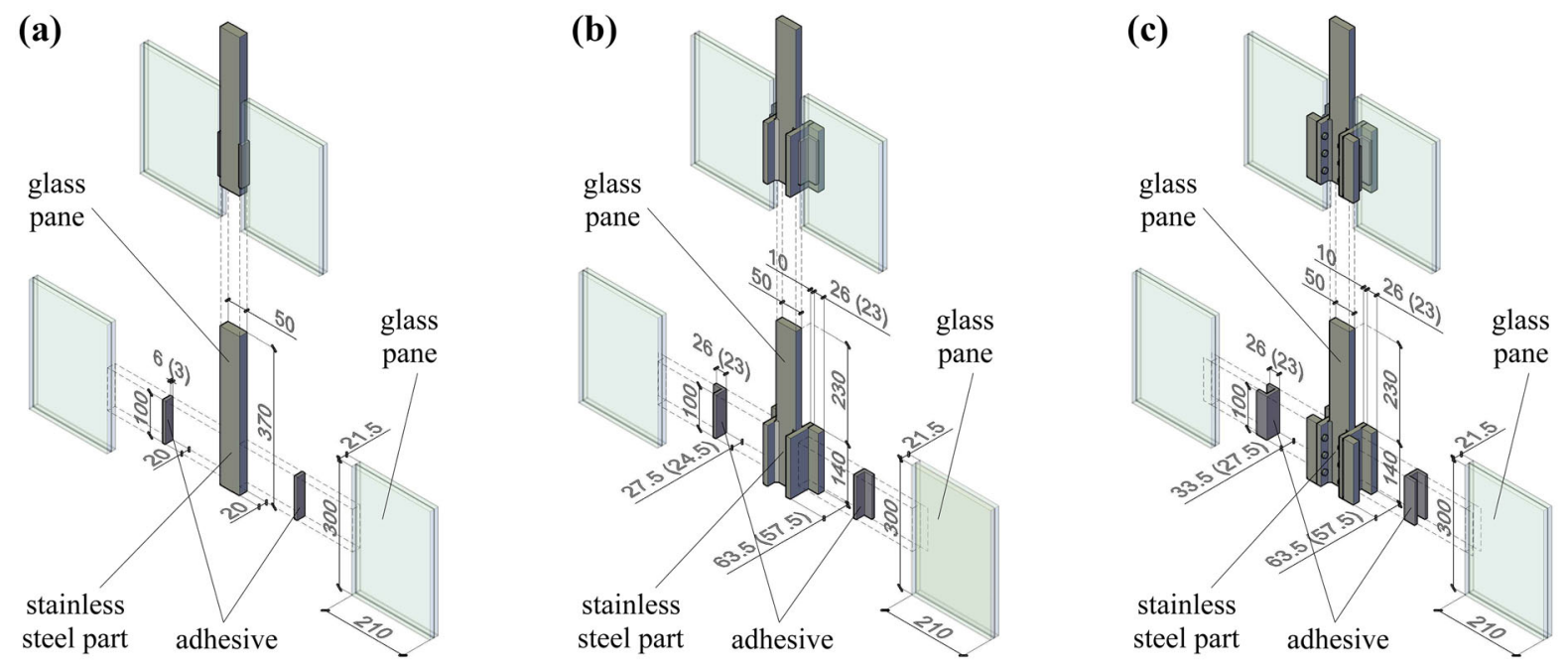

Fig. 6 Sketches of the specimens for linear adhesive connections with a rectangular, b L-shaped and $\mathbf{c}$ U-shaped cross section of the joint tested under shear loading

angular cross section of the adhesive joints, a $370 \mathrm{~mm}$ long, $50 \mathrm{~mm}$ wide and $20 \mathrm{~mm}$ thick stainless steel sheet is used (see Fig. 6a). The length is chosen in order to have enough space for connecting the displacement transducers. The width is required to provide a large enough clamping surface. For the specimens with Lshaped and U-shaped cross sections of the adhesive joints (see Fig. 6b, c), the stainless steel parts consist of the same sheets as in the case of the specimens with rectangular joint cross section, to which additional elements are welded on both sides towards the glass panes. These welded elements are similar to those used for the specimens tested under tensile loading and consist of $140 \mathrm{~mm}$ long and $10 \mathrm{~mm}$ thick stainless steel sheets with screwed stainless steel elements on one side for the L-shaped joints and on both sides for the U-shaped ones. The dimensions of the linear adhesive joints are the same as in the case of the tensile and of the compressive tests.

The specimens are tested in a standing position as illustrated in Fig. 7. Each of the two glass panes are hold down with two square hollow section bars $(40 \mathrm{~mm} \times 40 \mathrm{~mm} \times 5 \mathrm{~mm})$ in order to avoid a rotation during loading. A lateral restraint at the bottom of the glass panes is realised with steel sheets as in the case of the specimens tested under tensile loading. The direct contact between the metal parts and the glass panes is avoided by placing $3 \mathrm{~mm}$ thick elastomeric layers between the two materials. The load is applied

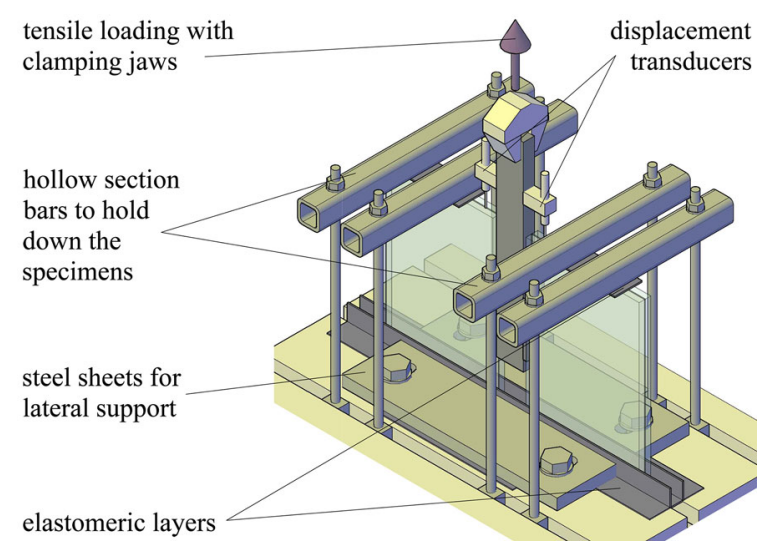

Fig. 7 Descriptive sketch of the test setup used for linear adhesive joints under shear loading

with clamping jaws which pull the stainless steel parts upwards, parallel to the longer glass edges. The relative displacements between the stainless steel parts and each of the two glass panes are measured with transducers which are fixed on the stainless steel parts with weld pins.

\subsection{Manufacturing of the test specimens}

In the case of test specimens for adhesive connections, manufacturing steps (e.g. preparation of the substrate surfaces, mixing of the adhesives, assembling of the 
specimens) can have a high influence on the test results. For all specimens, without depending on the adhesive or on the cross section geometry, some essential steps are carried out before assembling. Firstly, the surfaces to be bonded on the two substrates are delimited with a tape in order to obtain a clean edge of the joints. Secondly, cleaners [Dow Corning ${ }^{\circledR}$ R40 (2012b) for specimens with silicone 1 and Sika ${ }^{\circledR}$ Cleaner P (2015) for those with silicone 2 and those with acrylic adhesive] are wiped over the surfaces to remove dust and residual grease. Thirdly, for the specimens with silicone joints, primers [Dow Corning ${ }^{\circledR} 1200$ OS (2012a) for the specimens with silicone 1 and Sika ${ }^{\circledR}$ Aktivator205 (2010) for those with silicone 2] are wiped over the stainless steel surfaces to increase the adhesive strength. For the specimens with acrylic joints an activator (Sika ${ }^{\circledR}$ ADPrep 2013) is wiped both over the stainless steel and over the glass surfaces. Immediately after assembling and before the curing starts, the joints are tooled with a spatula and the delimiting tapes are removed.

Different mixing procedures are applied for the three adhesives investigated in this article. For silicone 1, cartridges of $300 \mathrm{~g}$ are used. The base components and the catalyst component are mixed together in the cartridge with a spindle fixed on a drilling machine with adjustable number of revolutions. The application is then carried out with a hand application gun directly from the cartridge. Silicone 2 is mixed and applied with a dynamic mixer as used by façade companies which produce SSGS. This procedure ensures a proper mixing of the two components for the highly viscous material. In the case of the acrylic, the adhesive is applied from dual cartridges of $250 \mathrm{ml}$ with a compressed-air handgun. A specially designed nozzle ensures a proper mixing of the two components.

The assembling of the test specimens differs depending on the cross section geometry of the adhesive joints but is similar for the three investigated adhesives. The specimens with a rectangular joint cross section are assembled in a lying position. Firstly, the glass pane is fixed against a timber plank and the polytetrafluorethylene (PTFE) blocks which determine the joint thickness are brought in position. Secondly, an adhesive bead is applied on the glass edge, between the PTFE blocks, and the stainless steel sheet is pressed on the adhesive (see Fig. 8a). Finally, the joint is tooled with a spatula (see Fig. 8b), tapes are removed and the specimen is fixed with a screw clamp.
The specimens with an L-shaped joint cross section are assembled in a standing position. Firstly, the stainless steel parts are fixed between glued-laminated timber beams and the PTFE blocks are positioned in such a way that they can be easily removed at a later time. Secondly, the adhesive is applied on the stainless steel part (see Fig. 8c) and the glass pane is pressed both downwards and laterally on the adhesive towards the PTFE blocks. Finally, the glass pane is fixed with timber blocks and screw clamps (see Fig. 8d), the joint is tooled and the tapes are removed. The amount and the distribution of applied adhesive together with the way the glass pane is pressed on it are decisive for the final quality of the joint. This assembling procedure is chosen instead of a procedure where the glass pane is first fixed and the resulting gaps are then filled with adhesive because of the small thickness of the joints ( $6 \mathrm{~mm}$ for the silicones and $3 \mathrm{~mm}$ for the acrylic) and the subsequently occurring difficulty to inject and uniformly distribute the adhesive into the gaps.

The specimens with a U-shaped joint cross section are assembled in a similar way to those with the Lshaped joint cross section. After fixing of the stainless steel part and preparing of the adhesion surfaces (see Fig. 8e), the adhesive is applied inside the U-part between the PTFE blocks. In a next step, the glass pane is pressed downwards into the U-part, while the adhesive is distributed and the superfluous material is pressed outside laterally. An example of a finalised specimen is illustrated in Fig. 8f. A gap filling procedure is not used for the same reasons as in the case of the L-shaped joints.

The specimens for adhesive joints tested under compressive loading are manufactured in the exact same way as those tested under tensile loading. In the case of the specimens for joints tested under shear loading, the only difference results from the fact that two joints need to be produced. This is done in two steps. First, the joint between one glass pane and the stainless steel part is completed and the half-way finished specimen is left over night to cure. The next day, the joint between the stainless steel part and the second glass pane is produced. All test specimens are stored in a climatic chamber at $23{ }^{\circ} \mathrm{C}$ and $50 \%$ relative humidity for 28 days before testing, based on specifications in (ETAG 002) for H-specimens. 
(a)

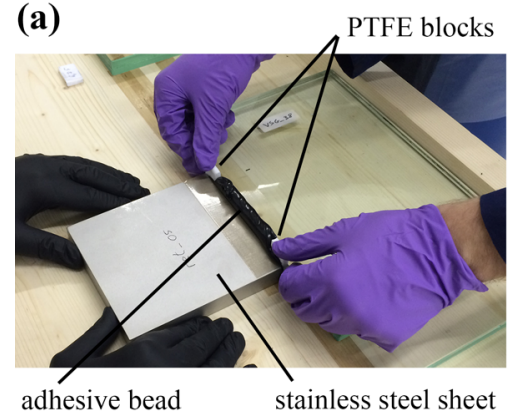

(b)

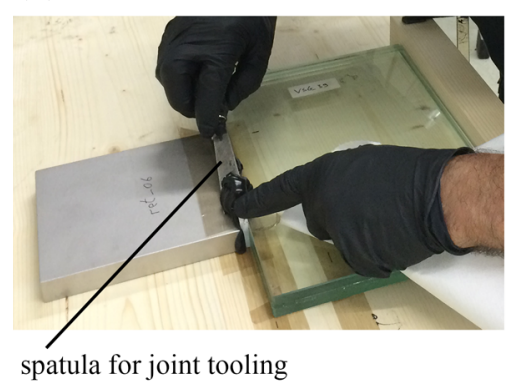

(c)

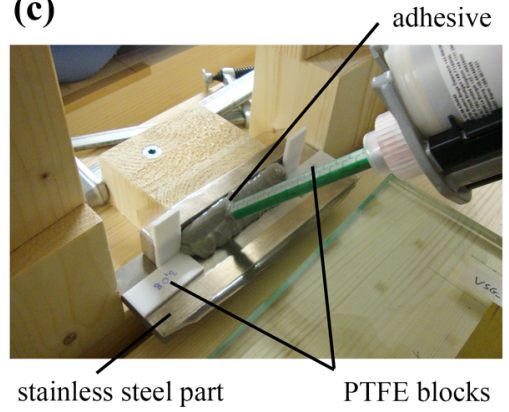

(d)

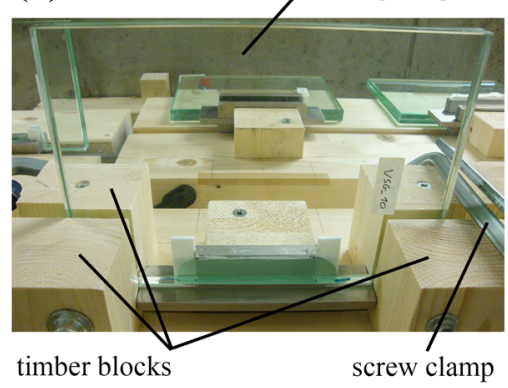

(e)

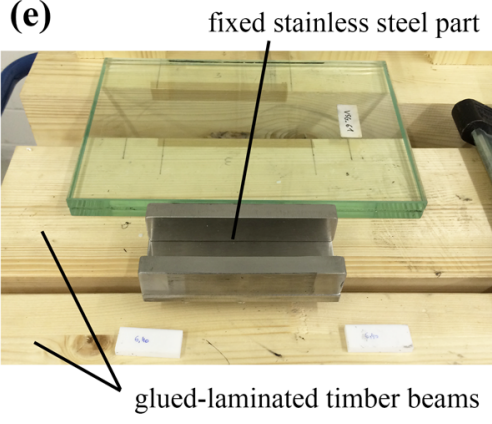

(f)

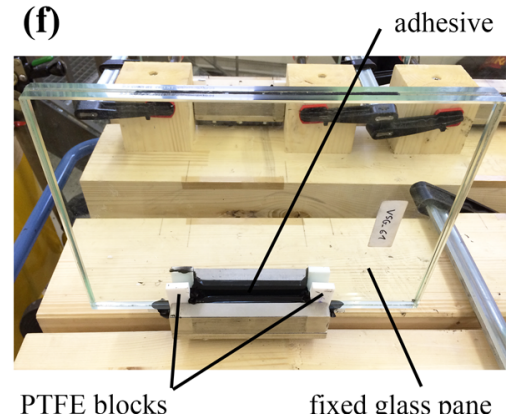

Fig. 8 Assembling of the test specimens: a adhesive application and $\mathbf{b}$ tooling for joints with rectangular cross section; $\mathbf{c}$ adhesive application and $\mathbf{d}$ fixing of the glass pane for joints with L-shaped cross section; e components before assembly and f specimen during curing for joints with $U$-shaped cross section

\section{Experimental results}

The results of the experimental study are presented in this section separately for the three different loading types. The mechanical behaviour of the adhesive joints with different cross section geometries and different adhesives is illustrated based on load versus displacement diagrams. The displacements in these diagrams are determined as the average of the values measured by the two displacement transducers used for each test specimen. In this way, eventual unequal deformations along the joints, which can result for example due to small differences in the joint thickness, due to small local voids or due to a slightly eccentric load application, are balanced. The deviation between the two averaged measurements varies for the different series. For tensile loading, differences of up to $\sim 0.2 \mathrm{~mm}$ are recorded before reaching the maximum loads and of up to $\sim 0.5 \mathrm{~mm}$ afterwards. In the case of compressive loading, the largest differences of up to almost $1.0 \mathrm{~mm}$ are recorded for the L-shaped joints with silicone adhesives. For the other joint cross sections, differences of less than $0.4 \mathrm{~mm}$ are measured. In the case of shear loading, where each transducer measures the displacements in one of the two laps in length direction of the joint, differences of up to $\sim 0.5 \mathrm{~mm}$ are recorded before reaching the maximum loads and of up to $\sim 1.0 \mathrm{~mm}$ afterwards.

Comparative discussions on the performance of joints with the same adhesive and different cross section geometry as well as of joints with different adhesives, but similar cross section geometry, are included in this section. The failure of the adhesive joints is discussed focusing on whether cohesive failure or failure due to loss of adhesion is occurring. Moreover, noteworthy findings concerning the interaction between adhesives and interlayer material are analysed.

\subsection{Linear adhesive joints under tensile loading}

The load versus displacement results from the tests on linear adhesive joints at the edge of laminated glass panes under tensile loading are represented in Fig. 9. 

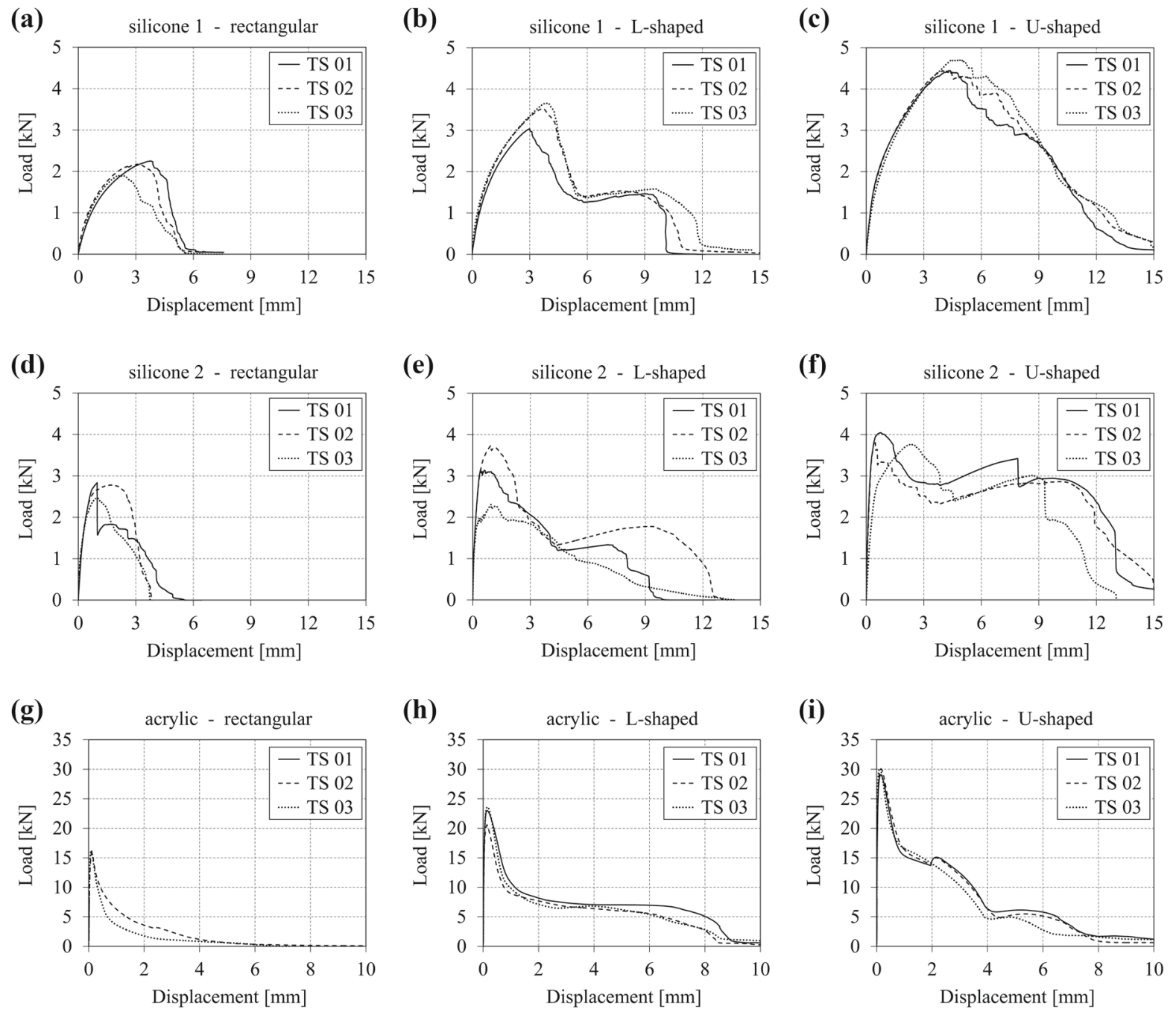

Fig. 9 Load versus displacement results from the experimental tests on linear adhesive joints under tensile loading

The results from each test series are plotted in a separate diagram for a clearer view. The same ranges are used on both the $\mathrm{x}$-axis and the $\mathrm{y}$-axis for the test series with the same adhesive and different joint cross sections. Moreover, the same axis ranges are used for both silicone adhesives to allow for a better comparison. The axis ranges for the acrylic adhesive are chosen differently, since significantly higher loads and lower displacements are recorded. For the specimens with silicone 1 and those with the acrylic adhesive, a good agreement between the curves for specimens from the same series can be noticed (Fig. 9a-c, g-i). In Fig. 9g only two curves are plotted since for one of the test specimens with acrylic adhesive and rectangular joint cross section no data was recorded by the displacement transducers. In the case of the specimens with silicone 2 (Fig. 9d-f), the results within a series vary slightly, especially for the series with L-shaped joint cross section (Fig. 9e). As expected due to the larger size of the bonding surfaces, the highest maximum loads are reached in the case of all three adhesives for specimens with U-shaped joint cross section, followed by the specimens with L-shaped joint cross section and those with rectangular joint cross section.

The results for the specimens with an L-shaped joint cross section exhibit for all three adhesives, but especially for silicone 1 (Fig. 9b) and for the acrylic adhesive (Fig. 9h), a certain remaining load-bearing capac- 
ity after failure of the joint part subjected to tensile stresses. This occurs because the part of the joint which is subjected to shear stresses allows for more displacement and therefore is further able to transfer loads. This failure mechanism is substantiated by the results of the tests on adhesive joints with rectangular cross section at the glass surface, which are briefly described in Sect. 5 of this contribution. Significantly lower displacements are recorded before failure for joints at the glass surface under tensile loading compared to shear loading. Results from these tests are discussed in Silvestru et al. (2018a) for the two silicones and in Silvestru et al. (2018b) for the acrylic adhesive.

For the specimens with U-shaped joint cross section, slightly different behaviours are observed for the three adhesives. In the case of the specimens with silicone 1 (Fig. 9c) the load does not drop immediately after the joint part subjected to tensile stresses fails first, but decreases almost with a constant gradient. This is not the case for the specimens with silicone 2, which show a similar behaviour to those with L-shaped joint cross section after failure of the joint part subjected to tensile stresses. A possible explanation for this discrepancy can be found in the different crack development pattern. On the one hand, the specimens with silicone 1 show cohesive ruptures with roughly profiled surfaces. On the other hand, in the case of silicone 2, the cohesive ruptures are situated nearer to the surface of one of the substrates and the surfaces of the damaged adhesive are quite smooth. Therefore, the adhesive joints with U-shaped cross section and silicone 1 can better transfer loads by friction after cohesive rupture occurs than those with silicone 2 . The load versus displacement curves for the specimens with U-shaped joint cross section and acrylic adhesive (Fig. 9i) exhibit two plateaus after the part of the adhesive joint subjected to tensile stresses fails first and the load starts to drop. This indicates that the part of the adhesive joint subjected to shear stresses does not fail simultaneously on both sides of the U-shaped joint.

Typical failure patterns for each of the specimen types (different adhesive and different cross section) investigated under tensile loading are provided in Fig. 10. For the specimens with silicone 1 only cohesive failure is noticed without depending on the cross section of the joint geometry. Tiny air inclusions can be noticed along the rupture surfaces shown in Fig. 10ac. These are assumed to be the result of the used mixing and application procedure described in Sect. 3.4.
Despite the low percentage of these inclusions compared to the bonded area, only a repetition of the tests on joints manufactured with a dynamic mixer would allow to exclude an influence of the inclusions on the joint performance.

The specimens with joints made of silicone 2 exhibit as well mainly cohesive failures. However, for some specimens also areas, on which a debonding from the glass surfaces occurs, can be noticed. On the glass edge itself, small areas with loss of adhesion are noticed for almost all specimens, as illustrated in the examples from Fig. 10d, f. For some specimens a complete adhesive debonding from the edge of one of the two laminated glass panes occurs (see example in Fig. 10e). In the case of some specimens with L-shaped and Ushaped joint cross sections, also a partial adhesion loss on the glass pane surfaces is noticed (see example in Fig. 10e). These combined failure modes explain the higher inconsistency in the load versus displacement results from Fig. 9 for the joints with silicone 2 compared to those for joints with silicone 1 .

The specimens with joints made of acrylic adhesive exhibit mixed failure modes, combining cohesive rupture and loss of adhesion, for all investigated cross section geometries. On the glass pane edges either only small areas fail adhesively, as illustrated by Fig. 10i for a joint with U-shaped cross section, or a complete debonding from one of the two laminated glass pane edges occurs, as in the case of the specimens shown in Fig. $10 \mathrm{~g}$, h. The failure modes of the joint parts subjected to shear stresses in the case of the specimens with L-shaped and U-shaped cross sections are rather due to loss of adhesion to the glass surfaces. Only on small parts of the bonding area a cohesive failure can be noticed in Fig. 10h, i.

In order to allow a better quantitative comparison of the failure modes noticed for the different specimen types (different joint cross sections and different adhesives) tested under tensile loading, the average percentages of cohesive rupture are provided in Table 2. For an approval of a structural adhesive according to ETAG 002 , at least $90 \%$ of the rupture should be located within the adhesive (cohesive rupture), while the percentage of rupture at the interface to one of the substrates (loss of adhesion) should not exceed $10 \%$. Considering the values in Table 2, only the specimens with silicone 1 meet this criterion. In the case of silicone 2 , single specimens meet the criterion as well, but the average percentage values of cohesive rupture are situated below $90 \%$. 
(a) silicone 1 - rectangular adhesive: cohesive failure interlayer: no visible failure

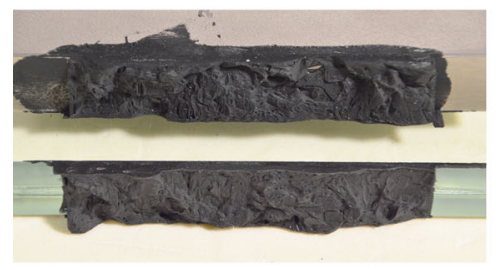

(d) silicone 2 - rectangular adhesive: mainly cohesive failure interlayer: no visible failure

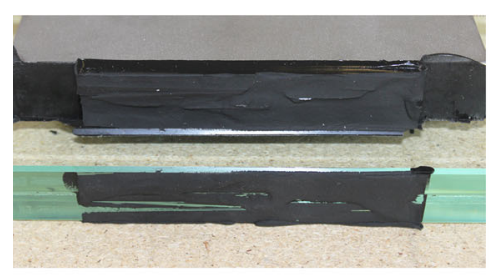

(g) acrylic - rectangular

adhesive: mainly loss of adhesion interlayer: delamination at glass edge

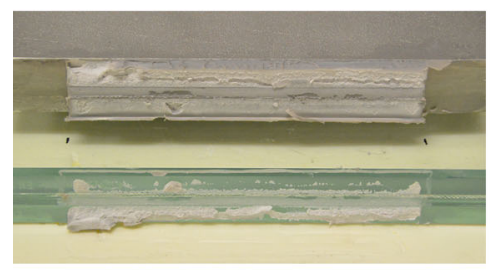

(b) silicone 1 - L-shaped

adhesive: cohesive failure

interlayer: no visible failure

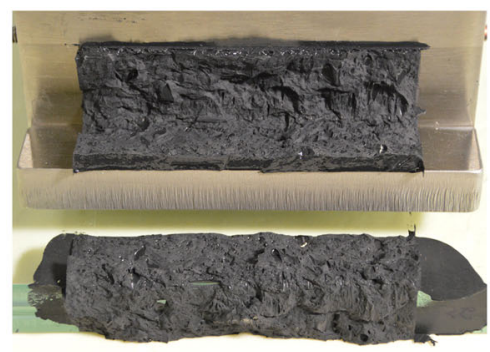

(e) silicone 2 - L-shaped

adhesive: mixed failure

interlayer: no visible failure

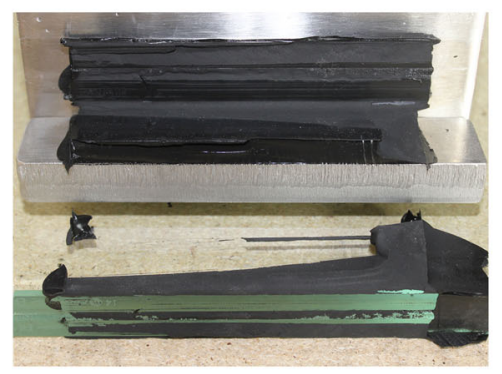

(h)

acrylic - L-shaped

adhesive: mainly loss of adhesion interlayer: delamination at glass edge

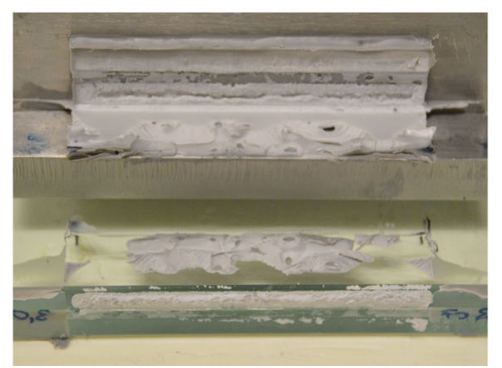

(c) silicone 1 - U-shaped

adhesive: cohesive failure

interlayer: no visible failure

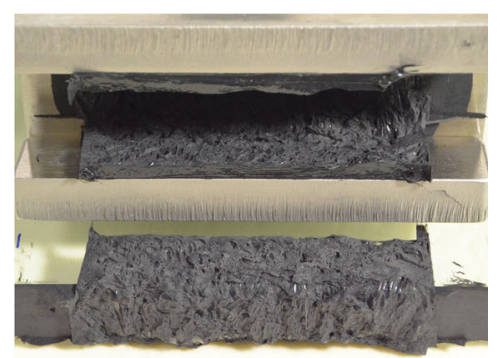

(f) silicone 2 - U-shaped

adhesive: mainly cohesive failure interlayer: no visible failure

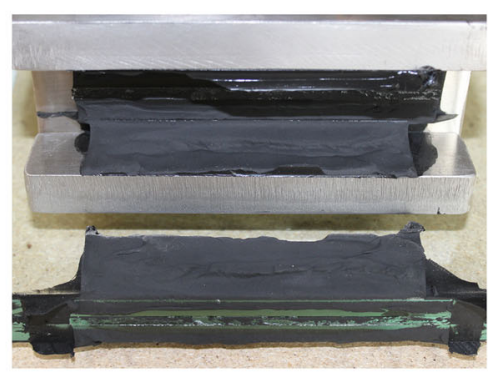

(i) acrylic - U-shaped

adhesive: mainly loss of adhesion interlayer: delamination at glass edge

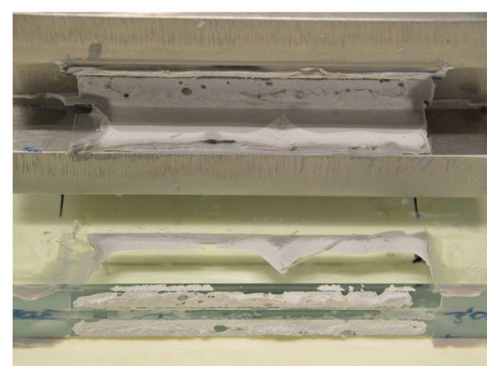

Fig. 10 Typical failure patterns from the experimental tests on linear adhesive joints under tensile loading

Table 2 Average percentage of cohesive rupture based on ETAG 002 for the different specimen types tested under tensile loading

\begin{tabular}{|c|c|c|c|c|c|}
\hline \multirow[t]{3}{*}{ Adhesive } & \multicolumn{5}{|c|}{ Average percentage of cohesive rupture } \\
\hline & \multirow[t]{2}{*}{ Rectangular cross section } & \multicolumn{2}{|c|}{ L-shaped cross section } & \multicolumn{2}{|c|}{ U-shaped cross section } \\
\hline & & Glass edge & Glass surface & Glass edge & Glass surface \\
\hline Silicone $1(\%)$ & 100 & 100 & 100 & 100 & 100 \\
\hline Silicone $2(\%)$ & $\sim 70$ & $\sim 70$ & $\sim 50$ & $\sim 70$ & $\sim 90$ \\
\hline Acrylic (\%) & $\sim 60$ & $\sim 60$ & $\sim 30$ & $\sim 60$ & $\sim 10$ \\
\hline
\end{tabular}




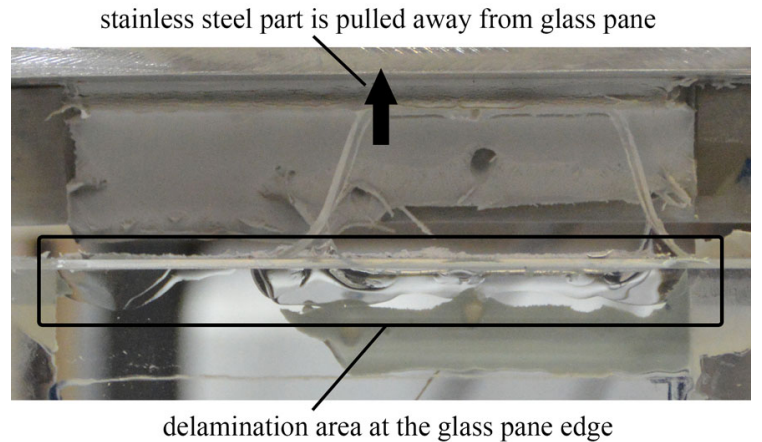

Fig. 11 Delamination during testing under tensile loading of a linear joint with acrylic adhesive and L-shaped cross section

For specimens with silicone adhesive joints subjected to tensile loading no influence on the interlayer of the laminated glass panes is noticed. However, for the specimens with acrylic adhesive joints, a beginning of delamination, as illustrated in Fig. 11, is observed. This proves a strong adhesion between the acrylic and the PVB interlayer. The delamination occurs only in direct vicinity of the bonded glass edge, without generating any defects, like bubble formation in the interlayer, further towards the middle of the glass pane.

\subsection{Linear adhesive joints under compressive load}

All the specimens with adhesive joints at the edge of laminated glass panes tested under compression are loaded up to $400 \mathrm{kN}$. Load versus displacement results from these tests are provided in Fig. 12 in separate diagrams for each series. For the test series with silicone adhesives (Fig. 12a-f), axis ranges up to $5 \mathrm{~mm}$ for the displacements and up to $100 \mathrm{kN}$ for the loads are chosen. After passing displacements of around $4 \mathrm{~mm}$, a tremble is noticed in the curves for the specimens with silicone adhesives because of internal ruptures in the adhesive material caused by high transverse strains. At displacements of around $6 \mathrm{~mm}$, which is the approximate joint thickness in the case of the silicone joints, a direct contact between the stainless steel parts and the glass edges is established and the load starts to increase significantly without further noticeable deformation. This part of the curves is not included in the diagrams, since studying the behaviour of the glass panes under compressive loading is outside the scope of these investigations. By comparing the load versus displacement results obtained for one joint cross section geometry with the two different silicone adhesives, it can be concluded based on the gradient of the curves that joints with silicone 2 behave slightly stiffer than joints with silicone 1 . The performed load cycles at the beginning of the compressive tests on the specimens with silicone adhesives show that the values for transferrable loads during a second loading are decreasing. This effect is known as the Mullins effect (Diani et al. 2009) and is occurring for most elastomers. Differences of up to around 50\% between the reached loads during a first loading cycle and during a second one are determined for displacements of $1.5 \mathrm{~mm}$ ( $25 \%$ strain).

In the case of all three adhesives, the gradient of the load versus displacement curves indicates that the joints with U-shaped cross section exhibit the highest stiffness, followed by those with L-shaped cross section and those with rectangular cross section. These differences in stiffness can be explained by the increasing confinement of the adhesive material for L-shaped and especially for $U$-shaped joints. In the case of the rectangular joints, the adhesive is easily pressed out laterally on all four sides of the joints. For the L-shaped joints a certain restraint is provided by the one-sided flange part. In the case of the U-shaped joints, a restraint is provided by the flange parts on both sides, so that the adhesive can only be pressed out easily on the face sides of the joints.

For the test series with acrylic adhesive (Fig. $12 \mathrm{~g}-$ i), axis ranges up to $3 \mathrm{~mm}$ for the displacements and up to $400 \mathrm{kN}$ for the loads are chosen. The specimens with acrylic adhesive behave significantly stiffer than those with silicone adhesive for all investigated joint cross section geometries. The load versus displacement curves obtained for the specimens with acrylic adhesive exhibit an S-shaped development. This could be an indication of yielding followed by hardening. The facts that a displacement of $3 \mathrm{~mm}$, which would be equal to the thickness of the joints, is not reached and also no significant increase of the load without an increase of displacement is noticed, confirm that no direct contact between the stainless steel parts and the glass edges is established up to loads of $400 \mathrm{kN}$. The curve for one specimen with rectangular cross section (TS 01 in Fig. $12 \mathrm{~g}$ ) ends at $300 \mathrm{kN}$, since the displacement transducers are removed at this load for the first specimen tested under compressive loading.

In the case of the adhesive joints at the edge of glass panes tested under compressive loading, the focus regarding failure patterns lays not on whether a failure 


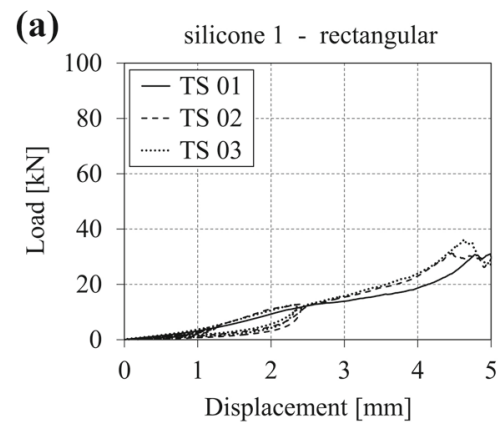

(d)

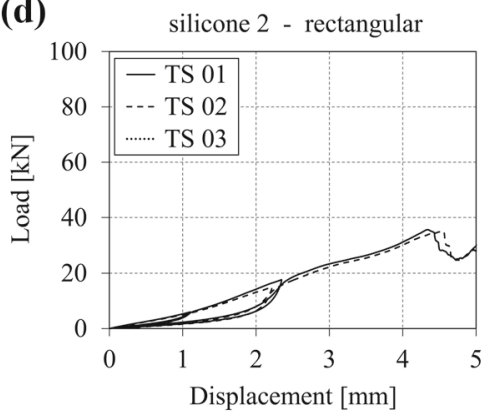

(g)

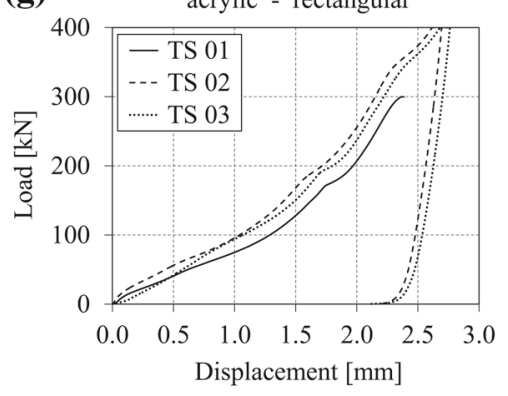

(b)

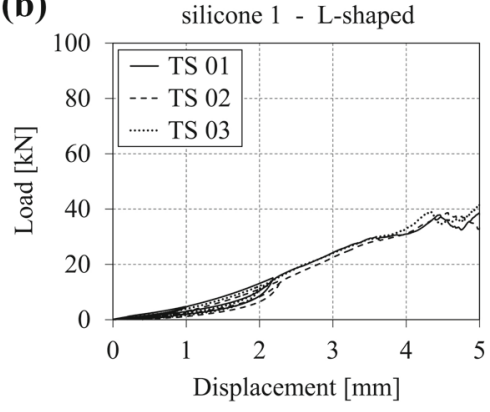

(e)

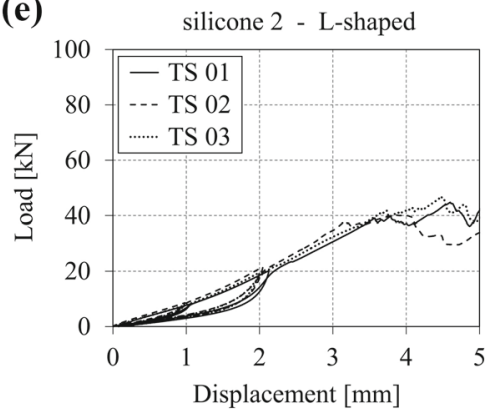

(h)

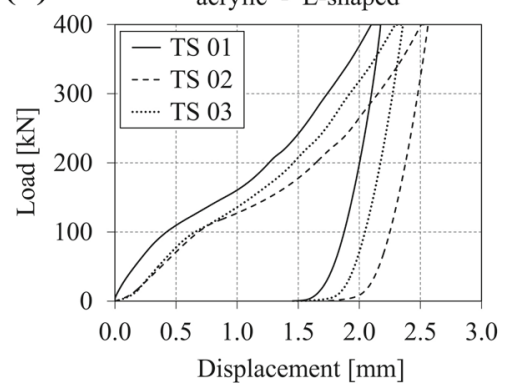

(c)

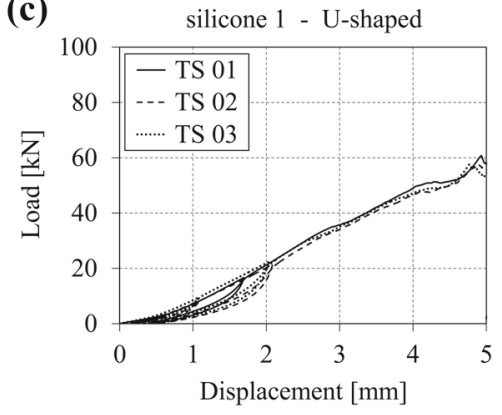

(f)

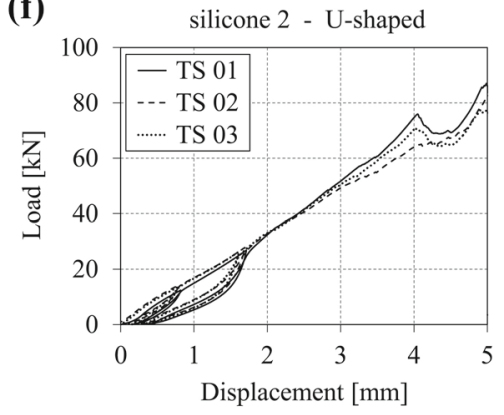

(i)

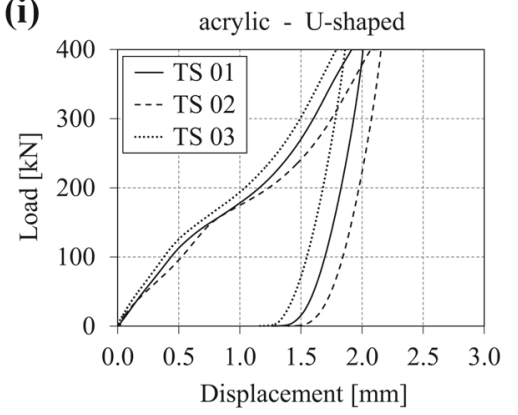

Fig. 12 Load versus displacement results from the experimental tests on linear adhesive joints under compressive loading

due to cohesive rupture within the adhesive or due to loss of adhesion to one of the substrates occurs, but rather on how the interaction between adhesives and interlayer is. Furthermore, since all three adhesives are considered almost incompressible (Poisson's ratios of at least 0.49 for the silicones and of 0.47 for the acrylic are recommended by the adhesive producers), the adhesive material has to be redistributed with increasing displacement. From the typical failure patterns provided in Fig. 13 it can be noticed, especially for the specimens with acrylic adhesive and rectangular or L-shaped joint cross section (Fig. 13g, h), that a part of the adhesive is pressed into the interlayer between the two laminated glass panes, while the rest is pressed laterally between the glass pane and the stainless steel components. At a certain load level, depending on the used adhesive as well as on the cross section geometry of the joint, a delamination of the interlayer from the glass panes occurs. The start of this process can be observed by formation of small visible bubbles during testing. The end results for the different specimen types after failure with both isolated bubbles as well as coalesced ones are visible in the failure patterns from Fig. 13.

In the case of the specimens with silicone adhesives, the stainless steel parts are in contact with the glass pane edges at the end of the tests. The part of the joints subjected to compressive stresses exhibits pronounced internal ruptures under high loads. This is noticeable 
(a) silicone 1 - rectangular

adhesive: cohesive failure

interlayer: bubbles + delamination

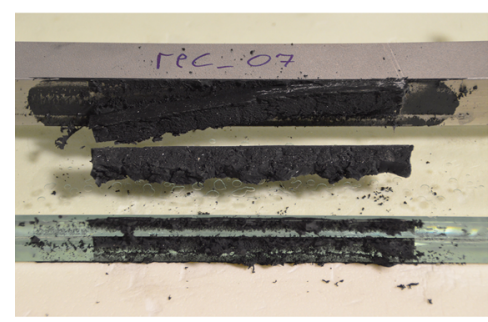

(d) silicone 2 - rectangular

adhesive: cohesive failure

interlayer: bubbles + delamination

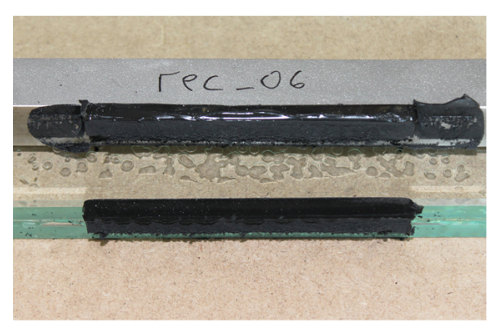

(g) acrylic - rectangular

adhesive: no visible failure

interlayer: bubbles + delamination

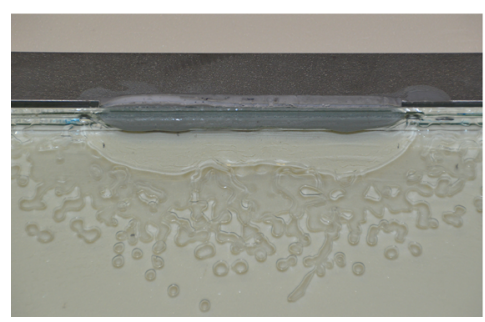

(b) silicone 1 - L-shaped

adhesive: cohesive failure

interlayer: bubbles + delamination

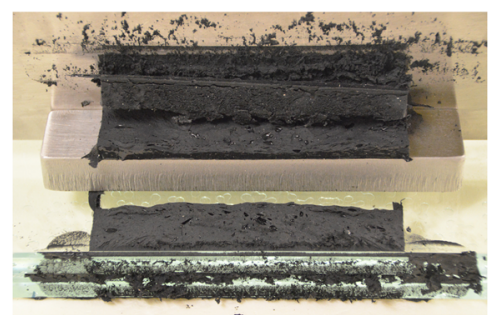

(e) silicone 2 - L-shaped

adhesive: cohesive failure

interlayer: bubbles + delamination

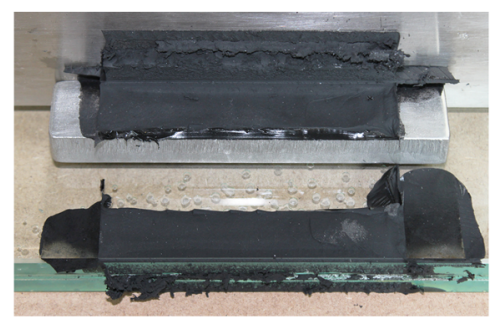

(h) acrylic - L-shaped

adhesive: no visible failure

interlayer: bubbles + delamination

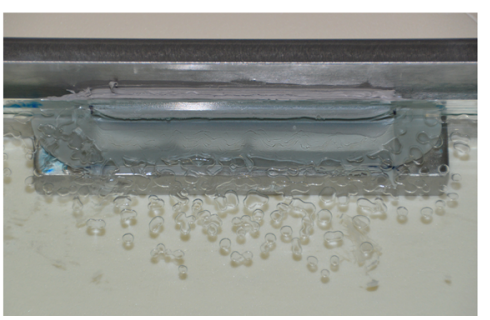

(c) silicone 1 - U-shaped

adhesive: no visible failure

interlayer: bubbles + delamination

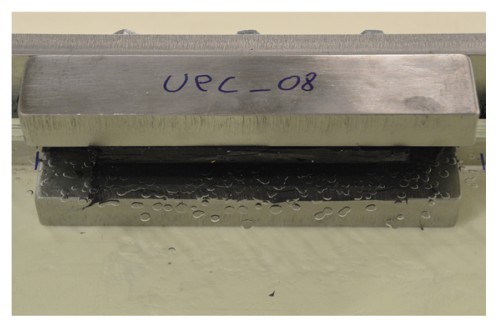

(f) silicone 2 - U-shaped

adhesive: no visible failure

interlayer: bubbles + delamination

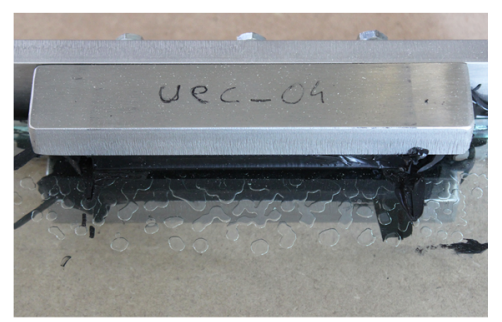

(i) acrylic - U-shaped

adhesive: no visible failure

interlayer: bubbles + delamination

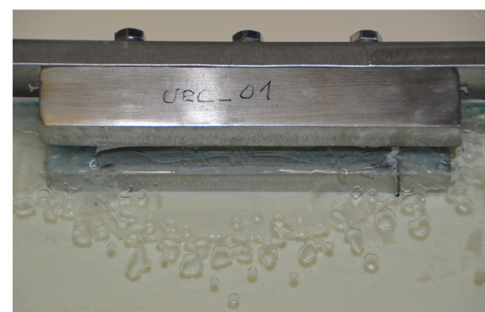

Fig. 13 Typical failure patterns from the experimental tests on linear adhesive joints under compressive loading

for the joints with rectangular cross section (Fig. 13a, d) and for those with L-shaped cross section (Fig. 13b, e), for which a complete rupture within the adhesive occurs. In the case of the specimens with U-shaped cross section (Fig. 13c, f), no full rupture results within the adhesive, because the lateral parts of the joint subjected to shear stresses allow for larger displacements than the joint thickness of $6 \mathrm{~mm}$. Moreover, no rotation of the joint, as in the case of the specimens with L-shaped joint cross section, is possible due to the symmetric geometry of these specimens. For the specimens with U-shaped joint cross section, adhesive is noticed to be pressed out at the two frontal sides of the joints in longitudinal direction. In the case of the specimens with acrylic adhesive, full rupture within the adhesive joints is not observed for any of the investigated cross section geometries. Furthermore, ruptures as in the case of the silicones are not noticed for the acrylic adhesive under higher compressive loads.

For completeness, average percentages of cohesive rupture are provided in Table 3 for the different specimen types tested under compressive loading. All the 
Table 3 Average percentage of cohesive rupture based on ETAG 002 for the different specimen types tested under compressive loading

\begin{tabular}{|c|c|c|c|c|c|}
\hline \multirow[t]{3}{*}{ Adhesive } & \multicolumn{5}{|c|}{ Average percentage of cohesive rupture } \\
\hline & \multirow[t]{2}{*}{ Rectangular cross section } & \multicolumn{2}{|c|}{ L-shaped cross section } & \multicolumn{2}{|c|}{ U-shaped cross section } \\
\hline & & Glass edge & Glass surface & Glass edge & Glass surface \\
\hline Silicone 1 & $100 \%$ & $100 \%$ & $100 \%$ & No rupture & No rupture \\
\hline Silicone 2 & $100 \%$ & $100 \%$ & $100 \%$ & No rupture & No rupture \\
\hline Acrylic & No rupture & No rupture & No rupture & No rupture & No rupture \\
\hline
\end{tabular}

specimens meet the criterion of at least $90 \%$ cohesive rupture defined in ETAG 002 for tensile and shear loading.

The start of bubble formation has been documented for the specimens with silicone 2 (see Fig. 14) and those with acrylic adhesive. In the case of the specimens with silicone 2, the bubble formation in the interlayer near the adhesive joint starts at loads of around $20-25 \mathrm{kN}$ for the joints with rectangular cross section and at loads of around $40-45 \mathrm{kN}$ for those with L-shaped cross section. For the joints with U-shaped cross section, the first bubbles are observed at around $100 \mathrm{kN}$. However, the formation of bubbles at lower loads in the area behind the stainless steel flanges cannot be excluded for the specimens with U-shaped joint cross section. In the case of the specimens with acrylic adhesive, the delamination starts at higher loads and is more pronounced than for the specimens with silicone adhesives. The first bubbles in the interlayer as a sign of delamination occur at around $40 \mathrm{kN}$ in the case of the specimens with rectangular joint cross section and at around $70-80 \mathrm{kN}$ for those with L-shaped joint cross section. In the case of the joints with U-shaped cross section, the first visible bubbles are noticed at around $110-120 \mathrm{kN}$. However, as in the case of the specimens with silicone adhesive, the formation of bubbles at lower loads for the specimens with U-shaped joint cross section cannot be excluded, since the visibility is restricted by the flanges of the stainless steel part. For the specimens with silicone 1 similar load values for the occurrence of the first bubbles as for the specimens with silicone 2 are expected due to the analogies observed for the two materials in terms of load versus displacement curves and failure modes.

Since no previous tests on adhesive joints at the edge of laminated glass panes under compressive loading are documented in literature, a comparison of the phenomenon of bubble formation in the interlayer to simi- lar results is not possible. Such effects are known from so-called tensile pancake tests (see for example Drass et al. 2017c) on rubber-like materials and are referred to as cavitation. Investigation results on materials for laminated connections on glass substrates subjected to tensile loading and proposed material models with regard to this topic are discussed by Drass et al. (2017c, 2018) and Santarsiero et al. (2017). Generally, such connections have a small thickness compared to their surface. The same is valid in the case of the interlayer in the laminated glass panes from the specimens investigated in this paper. Under tensile loading in thickness direction, the nearly incompressible materials are subjected to large hydrostatic stresses. Since the materials used for laminated connections or for interlayers cannot expand due to their high Poisson's ratio (nearly $0.5)$, bubbles are resulting. Considering these aspects, a possible explanation for the bubble formation observed in the case of the specimens tested under compressive loading is the following. By pressing the stainless steel components towards the laminated glass panes, some of the adhesive material is pressed into the interlayer and the two glass sheets are pushed away from each other. Therefore a similar hydrostatic stress state as in the case of the so-called tensile pancake tests is applied to the interlayer, which responds by bubble formation. This is not the case for tensile loading, because by pulling the stainless steel away from the laminated glass pane, the interlayer is stretched and the distance between the two glass sheets slightly reduces.

\subsection{Linear adhesive joints under shear loading}

The load versus displacement results for the specimens with adhesive joints at the edge of laminated glass panes tested under shear loading are given in Fig. 15 in separate diagrams for each test series. While in the case of the adhesive joints with L-shaped and U-shaped cross 


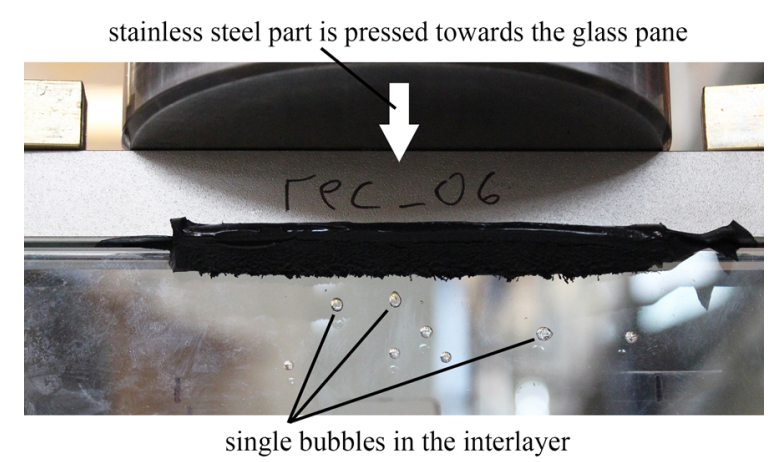

Fig. 14 Start of bubble formation in the interlayer (delamination) during testing under compressive loading of a linear joint with silicone 2 and rectangular cross section

sections subjected to tensile and compressive loading, parts of the joints were subjected to tensile and, respectively, compressive stresses and the other parts to shear stresses, in the case of the specimens tested under shear loading, all parts of the adhesive joints are subjected to shear stresses. The increasing load-bearing capacity with higher adhesion surface is confirmed, when comparing the curves for specimens with different cross section geometries to each other for one adhesive. For most specimens, the failure occurs almost simultaneously in both laps. However, in single cases, the failures in the two laps can occur slightly time shifted, as observable for TS 02 and TS 03 in Fig. 15a, TS 01 in Fig. 15 b or TS 02 in Fig. 15d for example.

In accordance to the results from the tensile and from the compressive tests for the two investigated silicones, the specimens with silicone 2 reach slightly higher maximum loads and behave a little stiffer. A good agreement between the curves with the same joint cross section geometry is given for the specimens with silicones, especially for those with rectangular and those with U-shaped joint cross sections. The agreement of the curves for joints with acrylic adhesive and the same joint cross section geometry is good until yielding, but shows larger discrepancies afterwards. In the case of the specimens with U-shaped cross section, certain loads can be transferred by friction also after failure of the adhesive.

Since in the case of the tests under shear loading all parts of the adhesive joints with different cross sections are subjected only to shear stresses, an additional eval- uation of the joint performance is carried out. For better comparison between the joints with different cross sections, the maximum reached loads are scaled for equal wetted areas on glass of $2 \times 2000 \mathrm{~mm}^{2}$. This area corresponds to the target wetted area in the case of the joints with rectangular cross section. The average scaled maximum loads are shown in Table 4 for the different joint types investigated under shear loading. These results show for the silicones, that L-shaped or U-shaped joint cross sections lead to slightly lower scaled loads. This is not the case for joints with the acrylic adhesive, since two of the specimens with rectangular cross section fail at lower loads due to loss of adhesion on the glass pane edges (see also curves in Fig. 15g).

An overview of typical failure patterns of the adhesive joints in the different types of specimens tested under shear loading is provided in Fig. 16. The failure patterns for the joints with silicones show mainly cohesive ruptures within the adhesive. For the specimens with silicone 2 , small local areas with failure due to loss of adhesion can be noticed on the glass pane edges (see Fig. 16e), as is the case for the specimens tested under tensile loading. The specimens with acrylic adhesive, however, show mainly failure due to loss of adhesion on the glass surfaces, independently on the geometry of the joint cross section (see Fig. 16g-i).

As in the case of the specimens tested under tensile loading and those tested under compressive loading, average percentages of cohesive rupture are provided in Table 5 for the different specimen types tested under shear loading in order to allow a quantitative comparison of the failure modes. The criterion from ETAG 002 of at least $90 \%$ cohesive rupture is met by both investigated silicones. The acrylic adhesive clearly fails to meet this criterion.

Additional to the almost complete debonding from both the glass edge and the glass surface areas, it can be observed for the specimens with acrylic adhesive that the interlayer is teared away during loading (see failure patterns in Figs. 16g-i, 17). This is on the one hand a sign of good adhesion between the acrylic and the PVB interlayer, on the other hand, however, it is a behaviour which is generally not desired, since it leads to delamination. For the specimens with silicone adhesive no such influence on the interlayer is noticed. 

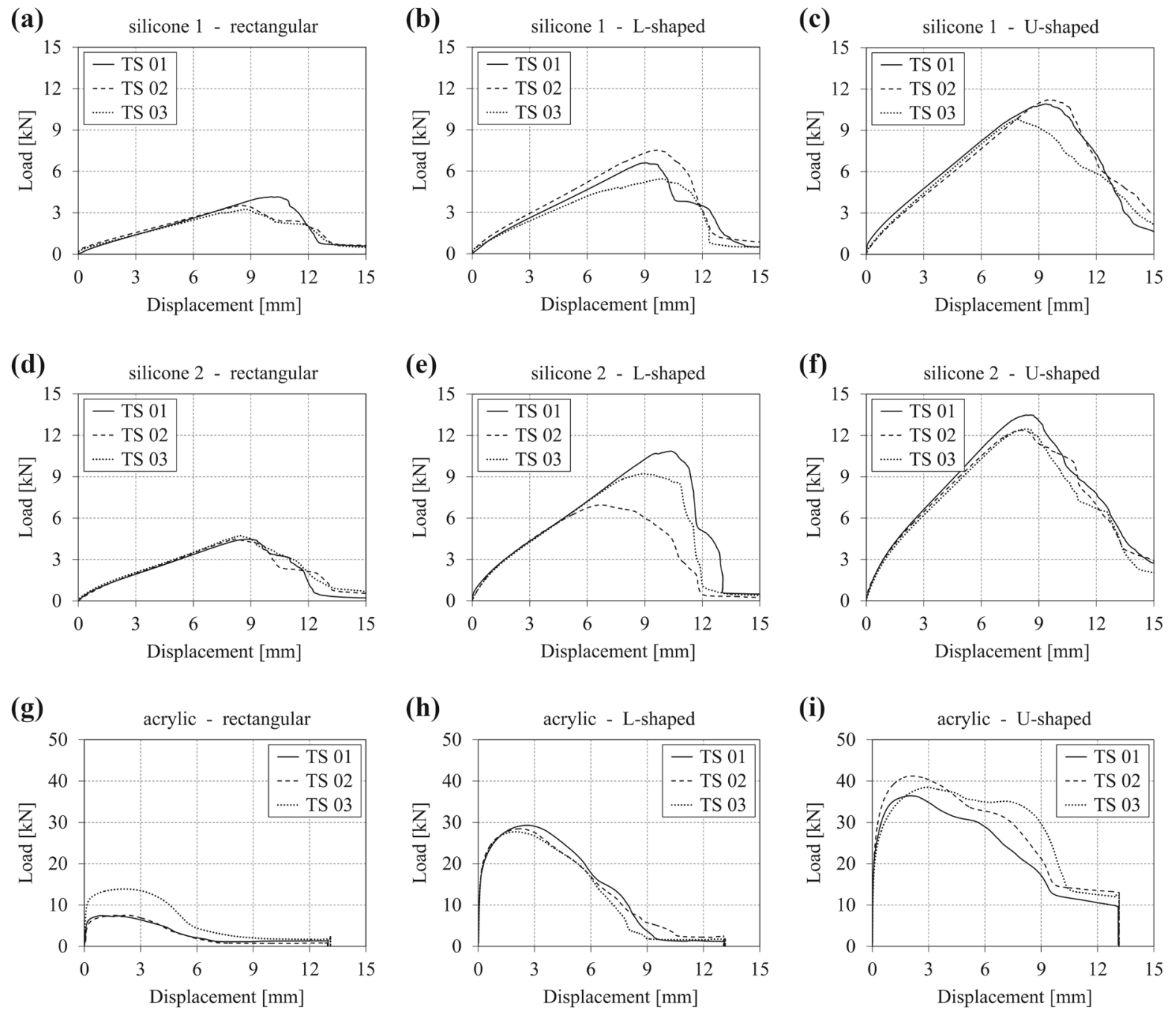

Fig. 15 Load versus displacement results from the experimental tests on linear adhesive joints under shear loading

Table 4 Average maximum loads for the different specimen types tested under shear loading, scaled for a wetted area on glass of $2 \times 2000 \mathrm{~mm}^{2}$

\begin{tabular}{llcc}
\hline Adhesive & \multicolumn{2}{c}{ Average maximum loads, scaled for a wetted area on glass of $2 \times 2000 \mathrm{~mm}^{2}(\mathrm{kN})$} \\
\cline { 2 - 4 } & Rectangular cross section & L-shaped cross section & U-shaped cross section \\
\hline silicone 1 & 3.474 & 3.107 & 3.433 \\
silicone 2 & 4.455 & 4.195 & 4.129 \\
acrylic & 9.248 & 13.407 & 12.713 \\
\hline
\end{tabular}


(a) silicone 1 - rectangular adhesive: cohesive failure interlayer: no visible failure

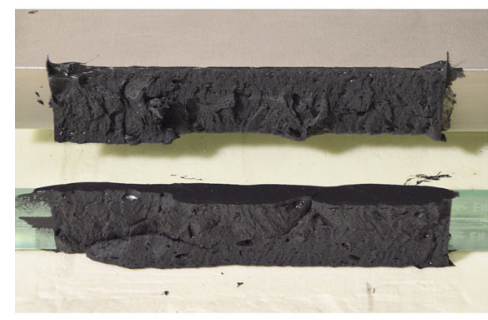

(d) silicone 2 - rectangular adhesive: cohesive failure interlayer: no visible failure

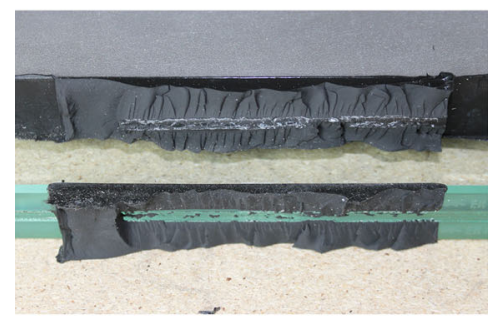

(g) acrylic - rectangular adhesive: loss of adhesion interlayer: delamination + tearing

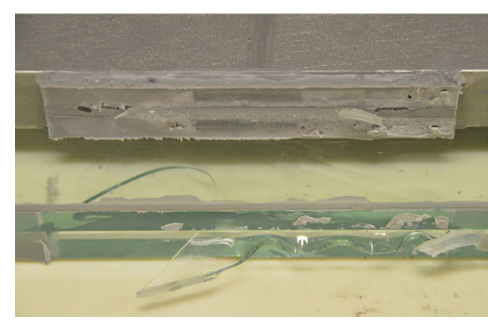

(b) silicone 1 - L-shaped adhesive: cohesive failure interlayer: no visible failure

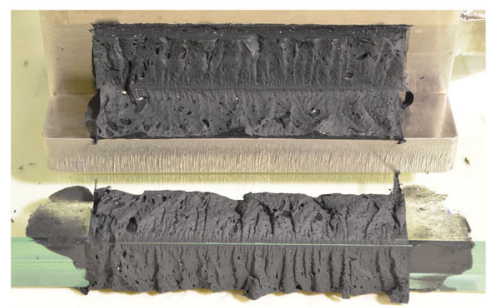

(e) silicone 2 - L-shaped

adhesive: cohesive failure interlayer: no visible failure

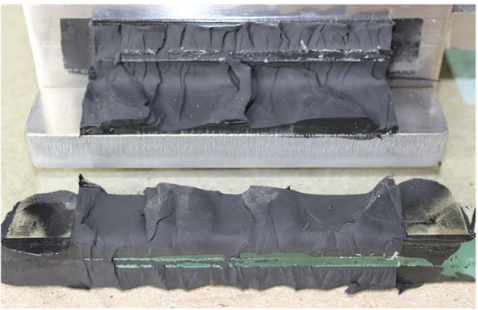

(h) acrylic - L-shaped adhesive: loss of adhesion interlayer: delamination + tearing

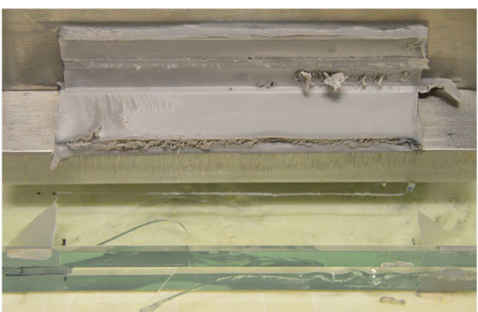

(c) silicone 1 - U-shaped

adhesive: cohesive failure interlayer: no visible failure

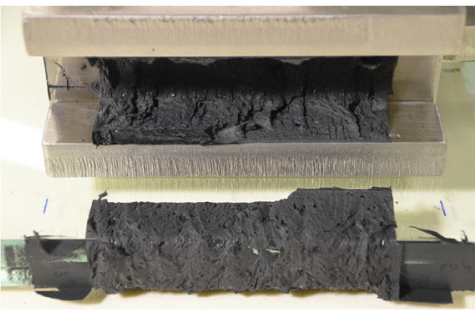

(f) silicone 2 - U-shaped

adhesive: cohesive failure interlayer: no visible failure

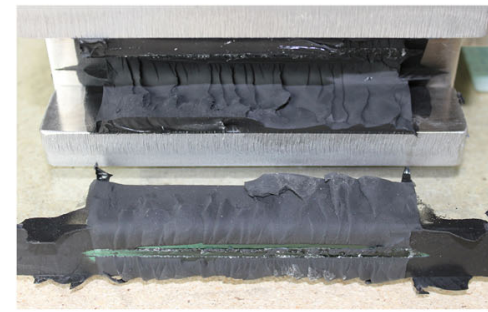

(i) acrylic - U-shaped

adhesive: loss of adhesion

interlayer: delamination + tearing

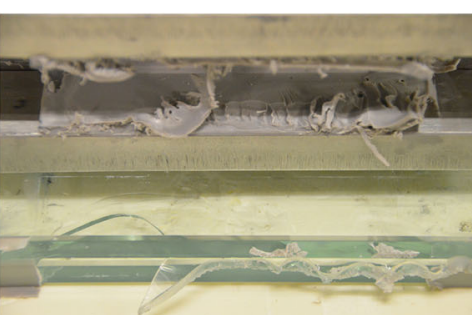

Fig. 16 Typical failure patterns from the experimental tests on linear adhesive joints under shear loading

Table 5 Average percentage of cohesive rupture based on ETAG 002 for the different specimen types tested under shear loading

\begin{tabular}{|c|c|c|c|c|c|}
\hline \multirow[t]{3}{*}{ Adhesive (\%) } & \multicolumn{5}{|c|}{ Average percentage of cohesive rupture } \\
\hline & \multirow[t]{2}{*}{ Rectangular cross section } & \multicolumn{2}{|c|}{ L-shaped cross section } & \multicolumn{2}{|c|}{ U-shaped cross section } \\
\hline & & Glass edge & Glass surface & Glass edge & Glass surface \\
\hline Silicone 1 & 100 & 100 & 100 & 100 & 100 \\
\hline Silicone 2 & $\sim 90$ & $\sim 90$ & $\sim 95$ & $\sim 90$ & $\sim 95$ \\
\hline Acrylic & $\sim 5$ & $\sim 5$ & $\sim 10$ & $\sim 5$ & $\sim 10$ \\
\hline
\end{tabular}




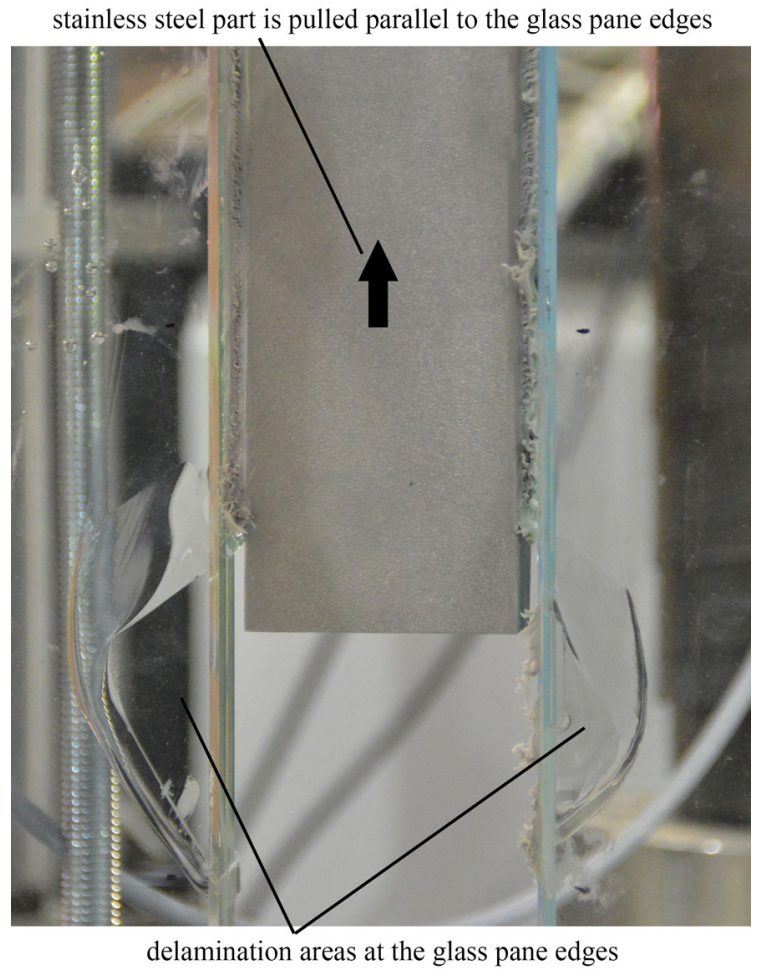

Fig. 17 Tearing of the interlayer and delamination during testing under shear loading of a linear joint with acrylic adhesive and L-shaped cross section

\section{Comparison with results \\ for adhesive joints on the glass pane surface}

The adhesion area on the edge of laminated glass panes is generally composed of the chamfered glass edges and the interlayer edge. Therefore, differences in the structural behaviour of adhesive joints with rectangular cross section at the edge of laminated glass panes compared to joints with a similar geometry on the flat glass surface can be expected. Experimental tests on adhesive joints with rectangular cross section geometry between stainless steel and glass surface substrates were carried out for the three investigated adhesives under tensile and under shear loading. The geometries of these test specimens and the used test setups are illustrated in Fig. 18a for tensile loading and in Fig. $18 \mathrm{~b}$ for shear loading. Furthermore, these experiments are described in detail along with obtained results for the silicones in Silvestru et al. (2018a) and for the acrylic adhesive in Silvestru et al. (2018b). The joint geometries used for the specimens with adhesive joints at the edge of laminated glass panes and rectangular cross section $(100 \mathrm{~mm} \times 20 \mathrm{~mm} \times 6 \mathrm{~mm}$ for the silicones and $100 \mathrm{~mm} \times 20 \mathrm{~mm} \times 3 \mathrm{~mm}$ for the acrylic) were also included in this experimental programme on adhesive joints at the glass surface. Similar surface pretreatments were applied on the substrate surfaces to be bonded in the case of both the joints at the edge of laminated glass panes and those at the glass surface.

The obtained results (load vs. displacement) from the two types of joints are compared to each other in separate diagrams for each adhesive in Fig. 19 for tensile loading and in Fig. 20 for shear loading. In the case of specimens with silicone 1 , the curves for the joints at the edge of laminated glass panes and those for the joints at the glass surface are in relatively good agreement for both tensile (see Fig. 19a) and shear loading (see Fig. 20a). The same can be noticed for specimens with silicone 2 under shear loading (see Fig. 20b). However, under tensile loading (see Fig. 19b), some of the specimens with silicone 2 fail at lower loads in the case of joints at the edge of laminated glass panes. This is due to the observed occasional partial loss of adhesion on the glass edges, which does not occur on the glass surface.

In the case of specimens with acrylic adhesive, the joints at the edge of laminated glass panes perform worse than those with similar joint geometry at the glass surface, both under tensile (see Fig. 19c) and under shear loading (see Fig. 20c). This is mainly due to loss of adhesion on the glass edge surfaces. Furthermore, a good adhesion of the acrylic to the interlayer material is noticed, which explains the smoother decay of load in the case of specimens with joints at the edge of laminated glass panes under shear loading.

\section{Conclusions}

For all three adhesives included in the presented investigations and for all three applied loading types, the specimens with U-shaped joint cross section allow for the transfer of the highest loads, followed by the specimens with L-shaped joint cross section and those with rectangular joint cross section. This tendency is in accordance with the differences in size of the adhesion area in the case of the three joint cross section geometries. From this observation, U-shaped cross sections should be recommended if the envisaged application and architectural design allows it. However, aspects concerning the 


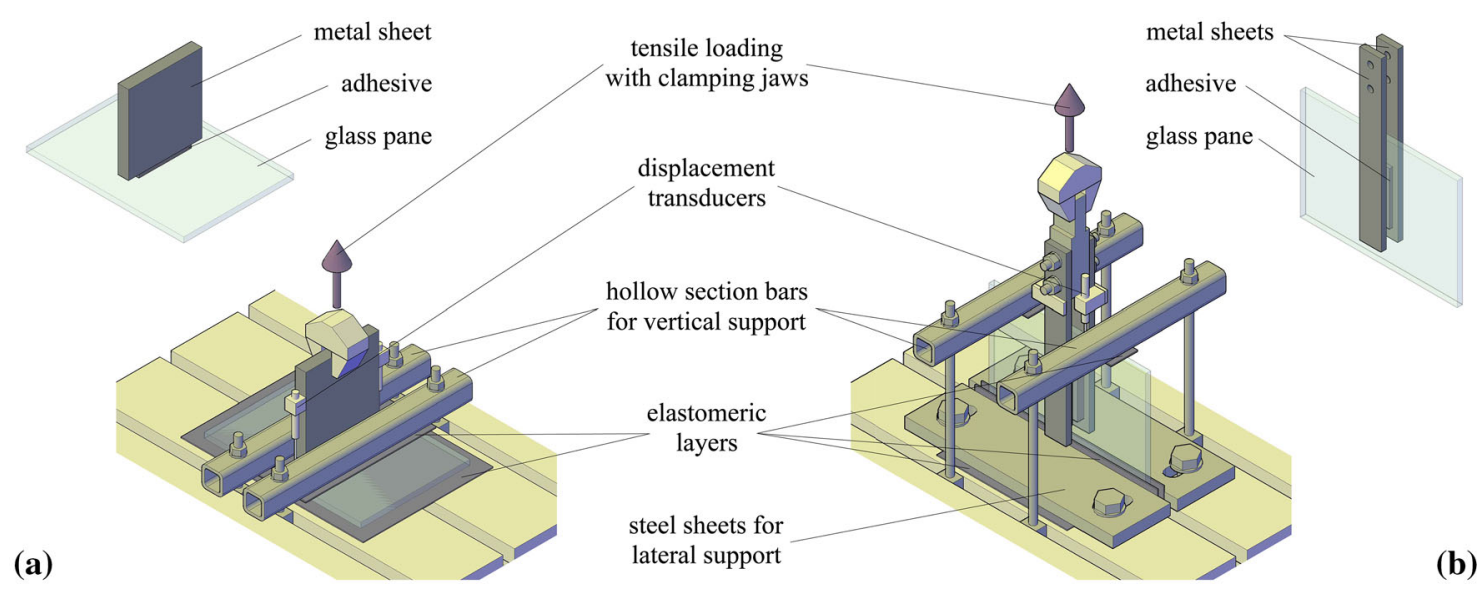

Fig. 18 Test specimens and test setups for linear adhesive joints at the glass pane surface investigated under tensile loading (a) and under shear loading (b)
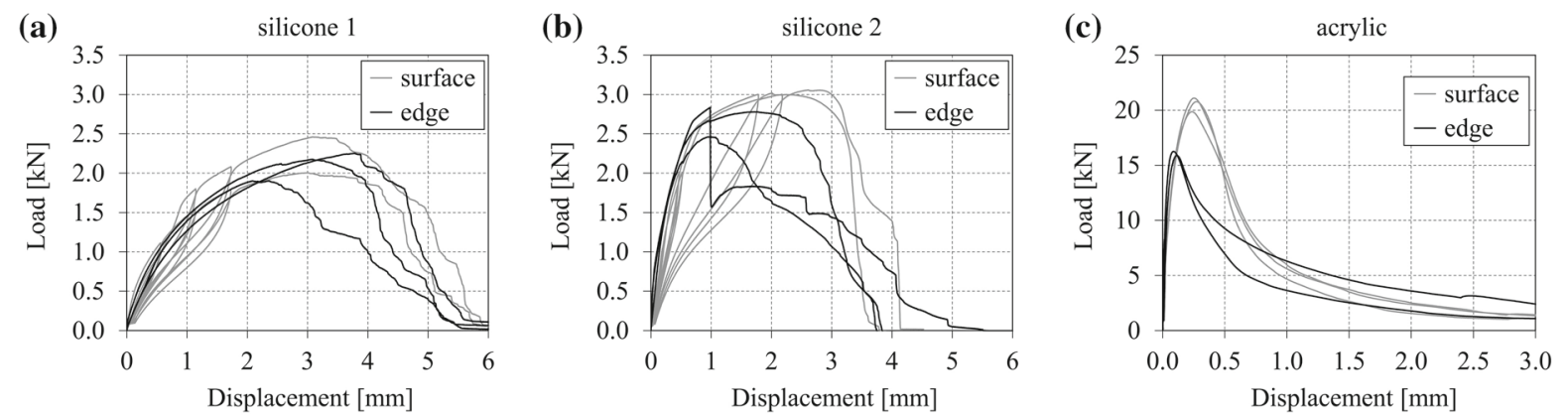

Fig. 19 Load versus displacement test results for linear adhesive joints with rectangular cross section under tensile loading: comparison between results obtained for joints at the edge of lam- inated glass panes with results obtained for joints on the glass pane surface for silicone 1 (a), silicone 2 (b) and acrylic (c) (a)

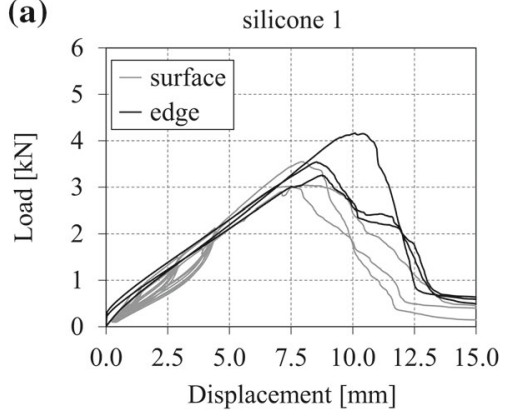

(b)

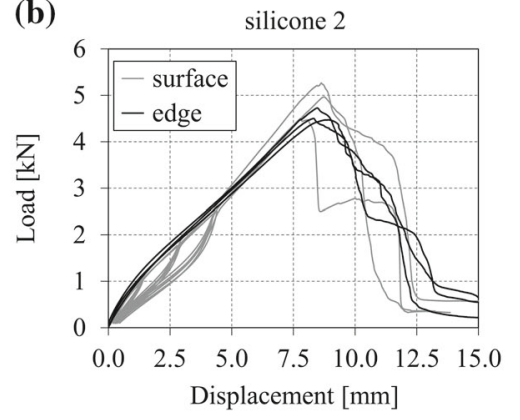

(c)

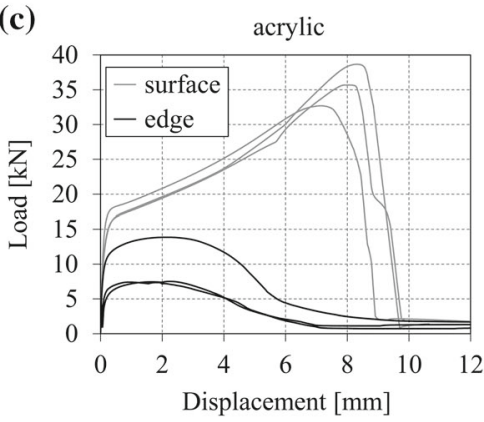

Fig. 20 Load versus displacement test results for linear adhesive joints with rectangular cross section under shear loading: comparison between results obtained for joints at the edge of laminated glass panes with results obtained for joints on the glass pane surface for silicone 1 (a), silicone 2 (b) and acrylic (c) 
manufacturing process should be considered as well. Joints with L-shaped or U-shaped cross sections are more difficult to produce, especially when small joint thicknesses are required. Joints with L-shaped cross section, generally, lead to an eccentric load transfer between the glass pane and the second adherend and therefore to a rotation of the joint during loading.

For the joints tested under tensile loading it is observed, that the part of the joints subjected to tensile stresses (part bonded directly to the glass pane edge) fails first, while the parts subjected to shear stresses (joints with L-shaped and U-shaped cross sections) allow for additional deformation and fail later. Under compressive loading, a direct contact is reached between the stainless steel parts and the glass panes for the specimens with silicone adhesives at loads between approximately 40 and $100 \mathrm{kN}$, depending on the adhesive and the joint cross section. For the specimens with acrylic adhesive, no direct contact is noticed until the maximum applied load of $400 \mathrm{kN}$. For joints with rectangular cross section subjected to tensile and to shear loading, results obtained for joints at the edge of laminated glass panes are compared to results obtained for joints at the glass pane surface. For specimens with silicone adhesives an equally good performance is noticed for both joint types under shear loading. Under tensile loading, a slightly worse behaviour in terms of maximum reached loads is observed for the joints at the edge of laminated glass panes. In the case of specimens with joints made of acrylic adhesive significantly lower loads are reached for the joints at the edge of laminated glass panes compared to those at the glass pane surface both under tensile and under shear loading.

In terms of failure modes and patterns, especially the interaction behaviour between the adhesives and the interlayer material offers interesting findings. Under compressive loading a delamination of the interlayer from the glass panes is noticed for all specimens, without depending on the adhesive or the joint cross section. Starting with a certain load level which is lower for the silicones and higher for the acrylic, isolated bubbles are generated in the interlayer because the adhesive is pressed between the two glass sheets. The loads at which the bubble formation starts in the case of the silicones are generally lower than the loads at which the stainless steel parts get in contact with the glass panes. This aspect substantiates the criticality of compressive loading on adhesive joints at the edge of lam- inated glass panes, despite a further load transfer possibility by form fit. With increasing load the bubbles grow together to larger areas of delamination. This phenomenon is more pronounced in the case of the specimens with acrylic adhesive and exhibits similarities to cavitation effects known from so-called tensile pancake tests on laminated connections. Under tensile and under shear loading, no delamination is noticed for the specimens with silicone adhesives. For those with acrylic adhesive the interlayer is teared out during loading as a result of a good adhesion between the two materials, however, without previous generation of bubbles. In terms of failure modes, the specimens with silicone 1 exhibit solely cohesive ruptures within the adhesive for all loading types. In the case of the specimens with silicone 2 , solely cohesive rupture occurs under compressive loading, while under shear loading the percentage of cohesive rupture averages over $90 \%$. Under tensile loading, although the rupture is situated mainly within the adhesive, the percentage of cohesive rupture is below the value of $90 \%$ requested in ETAG 002 . The specimens with acrylic adhesive do not exhibit a rupture under compressive loading, while under tensile loading and especially under shear loading the failure is mainly due to loss of adhesion to the glass substrates.

The results discussed in this article represent a basis for further investigations and developments on linear adhesive connections at the edge of laminated glass panes. All the presented experiments are performed under ambient conditions. Especially for applications in the façade area, experiments under different temperatures and for different ageing conditions should be carried out in a further step. These more extreme conditions are expected to have a significant influence on the interaction between adhesives and interlayer because of the sensitivity of these materials to such parameters. Regarding compressive loading, it is suggested to investigate the observed cavitation effects in detail in order to assess to what extent the bubbles are generated within the interlayer material or at the interface between interlayer and glass sheets. In either of the two cases, for application of such joints these effects need to be avoided because of their negative impact both from a structural and an aesthetical point of view.

Acknowledgements Open access funding provided by Graz University of Technology. This research was carried out at Graz 
University of Technology as part of the FFG research Project No. 838561. The authors would like to acknowledge the collaboration with Waagner-Biro Stahlbau AG on this research project as well as the financial support from the Austrian Research Promotion Agency (FFG) and from Waagner-Biro Stahlbau AG. Furthermore, the authors acknowledge the support of the Laboratory for Structural Engineering at Graz University of Technology in performing the experimental tests on the glass-metal connections. The support of Sika and Dow Corning with valuable advices on their adhesive products is highly appreciated. Moreover, the authors express their gratitude to Sika for providing the adhesive material and for facilitating the assembling of part of the test specimens in their laboratory facilities.

\section{Compliance with ethical standards}

Conflict of interest On behalf of all authors, the corresponding author states that there is no conflict of interest.

Open Access This article is distributed under the terms of the Creative Commons Attribution 4.0 International License (http:// creativecommons.org/licenses/by/4.0/), which permits unrestricted use, distribution, and reproduction in any medium, provided you give appropriate credit to the original author(s) and the source, provide a link to the Creative Commons license, and indicate if changes were made.

\section{References}

Abeln, B., Preckwinkel, E., Yandzio, E., Heywood, M., Eliasova, M., Netusil, M., Greiner, C.: Development of innovative steel-glass structures in respect to structural and architectural design (Innoglast). Technical report. Publication office of the European Union, Luxembourg (2013)

ASTM C 1401-02: Standard guide for structural sealant glazing. American Society for Testing Materials (2002)

Belis, J., Van Hulle, A., Out, B., Bos, F., Callewaert, D., Poulis, H.: Broad screening of adhesives for glass-metal bonds. In: Vitkala, J. (ed.) Glass Performance Days, Tampere, pp. 286289 (2011)

Cupac, J., Martens, K., Nussbaumer, A., Belis, J., Louter, C.: Experimental investigations of multi-span post-tensioned glass beams. Glass Struct. Eng. 2, 3-15 (2017). https://doi. org/10.1007/s40940-017-0038-5

Cruz, P., Pequeno, J., Lebet, J.P., Mocibob, D.: Mechanical modelling of in-plane loaded glass panes. In: Bos, F., Louter, C., Veer, F. (eds.) Challenging Glass, Delft, pp. 439-448 (2008)

Diani, J., Fayolle, B., Gilormini, P.: A review on the Mullins effect. Eur. Polym. J. 45, 601-612 (2009). https://doi.org/ 10.1016/j.eurpolymj.2008.11.017

Dias, V., Odenbreit, C., Hechler, O., Scholzen, F., Ben Zineb, T.: Development of a constitutive hyperelastic material law for numerical simulations of adhesive steel-glass connections using structural silicone. Int. J. Adhes. Adhes. 48, 194-209 (2014). https://doi.org/10.1016/j.ijadhadh.2013.09.043

Dispersyn, J., Belis, J.: Numerical research on stiff adhesive point-fixings between glass and metal under uniaxial load. Glass Struct. Eng. 1, 115-130 (2016). https://doi.org/10. 1007/s40940-016-0009-2
Dispersyn, J., Hertele, S., De Waele, W., Belis, J.: Assessment of hyperelastic material models for the application of adhesive point-fixings between glass and steel. Int. J. Adhes. Adhes. 77, 102-117 (2017). https://doi.org/10. 1016/j.ijadhadh.2017.03.017

Doebbel, F., Neubauer, D., Rudolf, B., Wagner, W.: Höherfeste Silikonverklebungen am Beispiel einer Glas-FinAnwendung. In: Weller, B., Tasche, S. (eds.) Glasbau 2014, pp. 47-56. Ernst \& Sohn, Berlin (2014)

Dow Corning ${ }^{\circledR} 1200$ OS Primer: UV Traceable_-Primer for silicone adhesives and sealants. Product data sheet, Dow Corning Corporation (2012)

Dow Corning ${ }^{\circledR} 993$ Structural Glazing Sealant: Two part silicone rubber. Product data sheet, Dow Corning Corporation (2014)

Dow Corning ${ }^{\circledR}$ R40 Universal Cleaner. Product data sheet, Dow Corning Corporation (2012)

Drass, M., Schwind, G., Schneider, J., Kolling, S.: Adhesive connections in glass structures - part I: experiments and analytics on thin structural silicone. Glass. Struct. Eng. 3, 39-54 (2017a). https://doi.org/10.1007/s40940-017-0046-5

Drass, M., Schwind, G., Schneider, J., Kolling, S.: Adhesive connections in glass structures-part II: material parameter identification on thin structural silicone. Glass. Struct. Eng. 3, 55-74 (2017b). https://doi.org/10.1007/ s40940-017-0048-3

Drass, M., Schneider, J., Kolling, S.: Damage effects of adhesives in modern glass facades: a micro-mechanically motivated volumetric damage model for poro-hyperelastic materials. Int. J. Mech. Mater. Des. (2017c). https://doi.org/10.1007/ s10999-017-9392-3

Drass, M., Schneider, J., Kolling, S.: Novel volumetric HELMHOLTZ free energy function accounting for isotropic cavitation at finite strains. Mater. Des. 138, 7189 (2018). https://doi.org/10.1016/j.matdes.2017.10.059

EN 10088-4: Stainless steels-Part 4: technical delivery conditions for sheet/plate and strip of corrosion resisting steels for construction purposes (2009)

ETAG 002: Guideline for European Technical Approval for Structural sealant glazing systems (SSGS). EOTAEuropean Organisation for Technical Assessment (2001)

Göppert, K., Paech, C.: Gläsernes Mahnmal zur Errinnerung an die Terrorattentate vom 11. März 2004 in Madrid. Stahlbau Spezial 42-46 (2008). https://doi.org/10.1002/ stab.200810031

Hagl, A.: Bemessung von strukturellen Silikon-Klebungen. Stahlbau 76, 569-581 (2007). https://doi.org/10.1002/stab. 200710060

Hagl, A.: Development and test logics for structural silicone bonding design and sizing. Glass Struct. Eng. 1, 131-151 (2016). https://doi.org/10.1007/s40940-016-0014-5

Haldimann, M., Luible, A., Overend, M.: Structural use of glass. Structural Engineering document SED10. International Association for Bridge and Structural Engineering IABSE, Zürich (2008)

Huveners, E.: Circumferentially adhesive bonded glass panes for bracing steel frames in facades. Ph.D. Thesis, Eindhoven University of Technology (2009)

Ioannidou-Kati, A., Santarsiero, M., de Vries, P., Teixeira de Freitas, S., Nijsse, R., Louter, C.: Mechanical behaviour of Transparent Structural Silicone Adhesive (TSSA) steel-to- 
glass laminated connections under monotonic and cyclic loading. Glass Struct. Eng. 3, 213-236 (2018a). https://doi. org/10.1007/s40940-018-0066-9

Ioannidou-Kati, A., Santarsiero, M., Louter, C.: Edge-laminated transparent structural silicone adhesive (TSSA) steel-toglass connections. In: Louter, C., Bos, F., Belis, J. (eds.) Challenging Glass 6, Delft, pp. 359-368 (2018b)

Machalicka, K., Vokac, M., Eliasova, M.: Influence of artificial aging on structural connections for façade applications. Int. J. Adhes. Adhes. 83, 168-177 (2018). https://doi.org/10. 1016/j.ijadhadh.2018.02.022

Martens, K., Caspeele, R., Belis, J.: Development of reinforced and posttensioned glass beams: review of experimental research. J. Struct. Eng. 142(5), 04015173 (2016). https:// doi.org/10.1061/(ASCE)ST.1943-541X.0001453

Mocibob, D.: Glass panel under shear loading - use of glass envelopes in building stabilization. Ph.D. Thesis, Ecole Polytechnique Federale de Lausanne - EPFL (2008)

Nhamoinesu, S., Overend, M., Silvestru, V.A., Englhardt, O.: The mechanical performance of adhesively bonded steel-glass composite panels: medium-scale tests and numerical models. In: Louter, C., Bos, F., Belis, J. (eds.) Challenging Glass 4 \& COST Action TU0905 Final Conference, Lausanne, pp. 169-276 (2014)

Nicklisch, F., Dorn, M., Weller, B., Serrano, E.: Joint study on material properties of adhesives to be used in load-bearing timber-glass composite elements. In: Schneider, J., Weller, B. (eds.) Engineered Transparency, Düsseldorf, pp. 271280 (2014)

Oikonomopoulou, F., Bristogianni, T., Veer, F., Nijsse, R.: The construction of the Crystal Glass Houses façade: challenges and innovations. Glass Struct. Eng. 3, 87-108 (2017). https://doi.org/10.1007/s40940-017-0039-4

Overend, M., Jin, Q., Watson, J.: The selection and performance of adhesives for a steel-glass connection. Int. J. Adhes. Adhes. 31, 587-597 (2011). https://doi.org/10. 1016/j.ijadhadh.2011.06.001

Peters, S.: Kleben von Glas und GFK für baukonstruktive Anwendungen. Ph.D. Thesis, Universität Stuttgart (2006)

Piculin, S., Nicklisch, F., Brank, B.: Numerical and experimental tests on adhesive bond behaviour in timber-glass walls. Int. J. Adhes. Adhes. 70, 204-217 (2016). https://doi.org/10. 1016/j.ijadhadh.2016.06.012

Puller, K., Sobek, W.: Load-carrying behaviour of metal inserts embedded in laminated glass. In: Bos, F., Louter, C., Nijsse, R., Veer, F. (eds.) Challenging Glass 3, Delft, pp. 307-314 (2012)

Santarsiero, M., Louter, C., Nussbaumer, A.: Laminated connections for structural glass components: a full-scale experimental study. Glass Struct. Eng. 2, 79-101 (2016a). https:// doi.org/10.1007/s40940-016-0033-2

Santarsiero, M., Louter, C., Nussbaumer, A.: Laminated connections for structural glass applications under shear loading at different temperatures and strain rates. Constr. Build. Mater. 128, 214-237 (2016b). https://doi.org/10.1016/j. conbuildmat.2016.10.045

Santarsiero, M., Louter, C., Nussbaumer, A.: Laminated connections under tensile load at different temperatures and strain rates. Int. J. Adhes. Adhes. 79, 23-49 (2017). https://doi. org/10.1016/j.ijadhadh.2017.09.002
Sika ${ }^{\circledR}$ ADPrep: Oberflächenvorbehandlung für Sika ${ }^{\circledR}$ ADP Klebstoffsysteme. Product data sheet, Sika Österreich $\mathrm{GmbH}$ (2013)

Sika ${ }^{\circledR}$ Aktivator-205: Pre-treatment agent for non-porous substrates. Product data sheet, Sika Schweiz AG (2010)

Sika ${ }^{\circledR}$ Cleaner P: Cleaning agent for non-porous substrates. Product data sheet, Sika Schweiz AG (2015)

SikaFast ${ }^{\circledR}$-5221 NT: Schnelles 2K-Klebstoffsystem für strukturelle Verklebungen. Product data sheet, Sika Schweiz AG (2013)

Sikasil ${ }^{\circledR}$ SG-550: High strength structural silicone adhesive. Product data sheet, Sika Schweiz AG (2016)

Silvestru, V.A., Englhardt, O., Schneider, J.: Investigations on linear silicone joints for glass-metal elements with composite structural behavior. In: Louter, C., Bos, F., Belis, J. (eds.) Challenging Glass 6, Delft, pp. 389-398 (2018a)

Silvestru, V.A., Drass, M., Englhardt, O., Schneider, J.: Performance of a structural acrylic adhesive for linear glass-metal connections under shear and tensile loading. Int. J. Adhes. Adhes. (2018b) (under review)

Staudt, Y., Schneider, J., Odenbreit, C.: Investigations of the material behaviour of bonded connections with silicone. In: Schneider, J., Weller, B. (eds.) Engineered Transparency, Düsseldorf, pp. 393-402 (2014)

Staudt, Y., Odenbreit, C., Schneider, J.: Failure behaviour of silicone adhesive in bonded connections with simple geometry. Int. J. Adhes. Adhes. 82, 126-138 (2018). https://doi.org/ 10.1016/j.ijadhadh.2017.12.015

Van Lancker, B., De Corte, W., Belis, J.: Material properties of a structural silicone for linear adhesive glass-metal connections. In: Bos, F., Louter, C., Belis, J. (eds.) Challenging Glass 5, Ghent, pp. 363-371 (2016)

Van Lancker, B., De Corte, W., Belis, J.: Mechanical properties of continuous adhesive glass-steel connections under monotonic and cyclic loading. Glass Struct. Eng. 3, 197211 (2018). https://doi.org/10.1007/s40940-018-0072-y

Voit, K., Tückmantel, P., Nicklisch, F., Kahlert, W.: Innovative Glaskonstruktionen im historischen Kontext, Schloss Grimma. In: Weller, B., Tasche, S. (eds.) Glasbau 2014, pp. 87-99. Ernst \& Sohn, Berlin (2014)

Weller, B., Döbbel, F., Nicklisch, F., Prautzsch, V., Rücker, S.: Geklebte Ganzglaskonstruktion für das Leibniz-Institut für Festkörper- und Werkstoffforschung in Dresden. Stahlbau 79, 34-40 (2010). https://doi.org/10.1002/stab.201001300

Wellershoff, F.: Nutzung der Verglasung zur Aussteifung von Gebäudehüllen. Ph.D. Thesis, RWTH Aachen (2006)

Publisher's Note Springer Nature remains neutral with regard to jurisdictional claims in published maps and institutional affiliations. 